\title{
Assessing the Wellbeing of the Spanish Elderly *
}

\section{Michele Boldrin, University of Minnesota, Federal Reserve Bank of Minneapolis, and CEPR Sergi Jiménez-Martín, Universitat Pompeu Fabra}

February 2, 2006

\begin{abstract}
In this paper we use a variety of data sources, both micro and macro, time series, cross section, and panel data to provide an empirical evaluation of the current level of economic wellbeing of the Spanish elderly, and of its determinants. We focus, in particular on the role played by the pension system and its generosity in terms of minimum pension supplements and non-contributive pensions. In an IV context, we find that actual Social Security benefits contribute substantially to explain income and consumption poverty levels and trends of low income and consumption percentiles. Thus we offer support to previous evidence for Spain emphasizing the role of minimum benefit policies.
\end{abstract}

Keywords: Welfare State, Social Security, Retirement, Income Inequality, Poverty.

JEL Class.: I3, H5, J14, J26

\footnotetext{
${ }^{*}$ We are grateful to the National Science Foundation, BEC2002-04294-C02-01 and SEJ2005-08783-C04-01 for financial support. Corresponding author: Sergi Jiménez-Martín, Department of Economics, UPF, Barcelona, Spain. e-mail: sergi.jimenez@upf.edu
} 


\section{Introduction}

Beginning in the late 1970s Spain has witnessed dramatic social, economic and demographic changes. Life expectancy has increased substantially and fertility rates have dropped to some of the lowest levels in the European Union. The Spanish public system of social insurance, of which the public pension system (Seguridad Social) is the main component, underwent a major reform in the middle 1980s and is now substantially more comprehensive and generous than it used to be. Finally, Spanish per capita income has grown continuously since the middle 1980s, on average at about a percentage point faster than the rest of the EU, and the difference has increased since the late 1990s; during the same period a large share of the older workers have been dismissed and lead to retire earlier while the unemployment rate soared first and then, since 1996, declined steadily to reach average European levels in the last three years.

In this chapter we document how the material well being of the Spanish elderly population has been affected by this multidimensional process of economic and social change. Our conclusion is that the elderly are remarkably better off now than thirty years ago, indeed that their relative wellbeing, vis-à-vis that of the rest of Spanish society, has increased dramatically and that, apart for the general economic evolution, this is due mostly to changes in the public pension and welfare system.

The rest of the document goes as follows. In section 2 we document the macroeconomic facts during the last decades. In section 3 we describe the Social Security background. The data and sources are commented in section 4. The wellbeing trends are shown in section 5. Sections 6 and 7 describe our methodology and section 8 present the main results from the analysis. Finally, section 9 offers some concluding remarks.

\section{The Facts}

\subsection{Macroeconomic Evolution}

Table 1 summarizes the Spanish macroeconomic evolution, in relation to the EU's average performances, since 1975. The basic facts for Spain are as follows. ${ }^{1}$ In the period immediately after the oil shock, 1975-1985, which coincides with the death of Francisco Franco and the beginning of the democratic transition, both the growth rate of GDP and the level of employment are well below the European average. This period corresponds to a dramatic "structural transition" in which a few million jobs are eliminated and the unemployment rate skyrockets to levels substantially above twenty percent. This was only partially a consequence of the two oil shocks; the collapse of the Franco regime lead to a spontaneous and unplanned "opening" of the economy, which preceded and anticipated the entrance into the EU of almost a decade. As a consequence of this broad restructuring process, productivity growth in Spain was by far more intense than the European average until the second half of the 1980s. In the period since 1985, the opposite process took place: productivity growth in Spain is slightly but persistently below the EU average, while GDP and employment grow, on average, faster than in the rest of Europe. The last ten years, in particular, have seen a spectacular increase in Spanish employment (five million additional jobs out of a total employment, in 1995, of about twelve millions) which has, nevertheless, come together with a very slow rate of growth in labor productivity. Inflation, on the other hand, has been slightly above the European average during the whole period, although the differential has reduced in recent years,

\footnotetext{
${ }^{1}$ Source: Eurostat. See Dolado et al. (1998) for further details.
} 
following the implementation first of the Maastricht pact and then of the Euro. Finally, real unit labor cost have been decreasing at about the EU average during the whole period.

Table 1: The Macroeconomic Scenario. (Annual percentage growth rates)

\begin{tabular}{lrrrrrrrr}
\hline \hline & \multicolumn{4}{c}{ Spain } & \multicolumn{5}{c}{ EU } \\
& $75-85$ & $85-90$ & $90-99$ & $99-04$ & $75-85$ & $85-90$ & $90-99$ & $99-04$ \\
\hline GDP real growth & 1.7 & 4.5 & 2.3 & 2.9 & 2.3 & 3.2 & 1.8 & 2.2 \\
Number employed & -1.6 & 3.3 & 1.0 & 2.2 & 0.1 & 1.4 & 0.2 & 1.0 \\
Average hours worked & - & -0.2 & -0.2 & -1.2 & - & -0.4 & -0.3 & -0.9 \\
GDP/number emp. & 3.3 & 1.2 & 1.3 & - & 2.2 & 1.7 & 1.6 & - \\
GDP/total hours worked & - & 1.4 & 1.6 & - & - & 2.1 & 1.9 & - \\
Consumer prices & 15.4 & 6.5 & 3.9 & 3.1 & 10.3 & 4.4 & 3.0 & 2.2 \\
Average earnings & 17.2 & 7.9 & 4.9 & 2.6 & 11.6 & 6.4 & 4.1 & 2.4 \\
Average real earnings & 1.6 & 1.4 & 0.9 & - & 1.2 & 1.9 & 1.1 & - \\
Average real labor costs & 2.1 & 0.5 & 0.6 & 3.2 & 1.5 & 1.4 & 1.1 & 2.8 \\
Real unit labor cost & -1.1 & -0.7 & -0.7 & -1.0 & -1.1 & -0.8 & -0.7 & -0.1 \\
\hline
\end{tabular}

What are the implications of these macroeconomic facts for our purposes? Basically that the relative economic position of Spain, and of the average Spaniard, has improved substantially, visá-vis that of the average European, during the last thirty years. The natural question to ask, therefore, is: did this improvement in the economic well being of the average Spaniard translate also into an improvement of the economic conditions of the elderly? The next figure reports the ratio of pension expenditure to GDP since 1965. It is apparent that this ratio has grown substantially for about thirty years and has flattened out and slightly decreased during the last ten years or so.

Is this dynamics of the pension/GDP ratio due only to demographic change or also to other factors? As the next subsection briefly shows, demographic change has been substantial in Spain, still it cannot fully account for the dramatic increase of the pension expenditure to GDP ratio. In the rest of the paper we try to identify the dimensions along which social policies have also made a difference, how they have interacted with demographic change and along which dimensions this interplay has affected the quality of life of Spanish elderly.

\subsection{Demographic scenario}

The three main factors determining the evolution of the size and composition of the population are fertility, mortality, and migration. In the absence, so far, of important migration flows ${ }^{2}$ it is the interaction between fertility and mortality that determines both the size of the working age population and its relation with the non-working age population (dependency ratios). In Table 2 we present estimates of the past (1950-2000) and projected (2000-2020) trends for the Spanish population. We report the size of the three main age-groups, which implicitly define dependency

\footnotetext{
${ }^{2}$ Things have rapidly be changing during the last five or eight years. The previously invisible flow of immigrants into Spain, has now become quite visible: we estimate there are about 3 million immigrants in Spain, out of a total population slightly less than 43 million. Very recent (2005) administrative and legislative changes, aimed at facilitating the admission of foreign workers and regularizing the position of about 800 thousands of them, may lead to an even more dramatic upsurge in the migration flow.
} 
Figure 1: Pension expenditure to GDP ratio

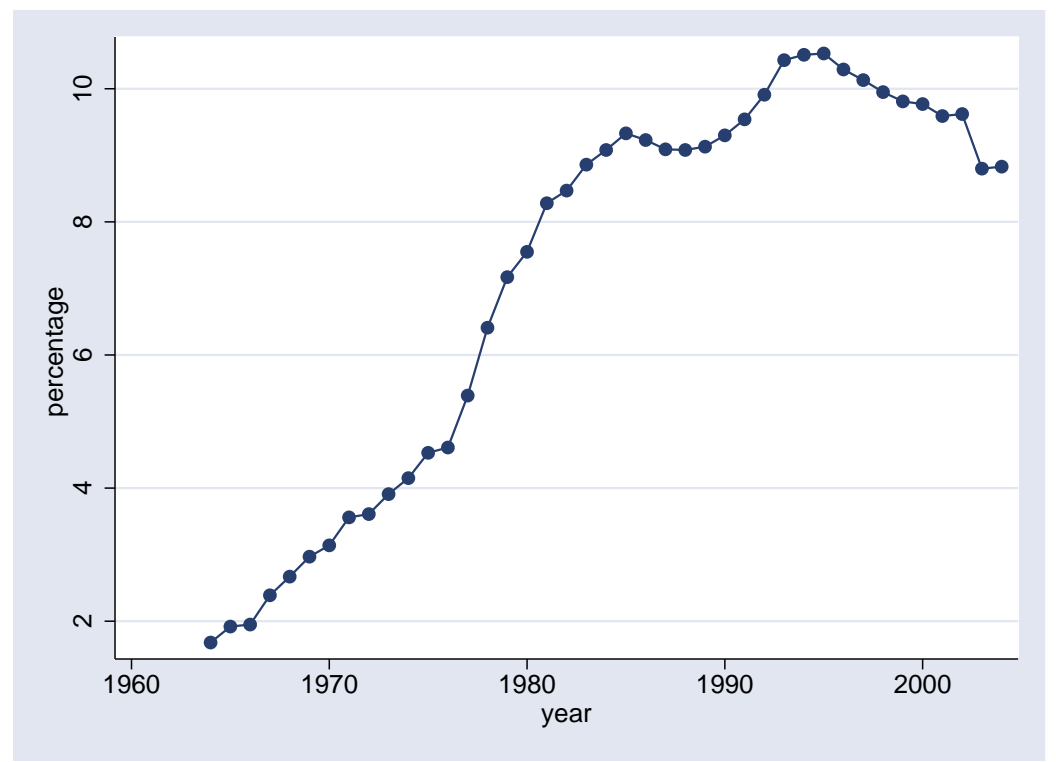

ratios, the synthetic fertility index (SFI), and the life expectancy at birth and at 65 for the two sexes separately.

In Spain, the overall dependency ratio (share of the inactive population over the active) has increased continuously since the late 1950s, but the reason for the increase has changed somewhere in the middle of the period. The fraction of the young, [0-14], in the population peaked in the 1970s and steadily decreased since. Currently, the size of each newborn generation is half the size of the same generation twenty years ago. Instead, the fraction of people who are $65+$ has grown steadily since the 1950s, has doubled by now and is expected to increase further in the future until it triples in 2020 and then almost quadruple by 2050 . This is due to the cumulation of two factors: the high fertility rates of the 1950s, and the steady increase in life expectancy at 65 . While the baby boom "wave effect" is temporary and will be gone by 2035-2040, the increase in life expectancy is widely believed to continue during the forthcoming decades; as a consequence, by 2050, life expectancy at 65 may be 5 to 7 years longer than it is now for either sex.

The observation made in the previous footnote about the dramatic upsurge of immigration since 1999-2000, gives us a measure of how biased the demographic picture of Table 2, which is based on official data available in 2002-2003, actually is. As mentioned, the current resident population of Spain is of about 43 million people, hence the table misses slightly less than 3 million people. These are all immigrants and, while they may not all belong to the central age group, plenty of informal evidence suggests most of them do, implying that the actual dependency ratio in Spain is, currently, substantially lower than the one reported in Table 2. Unofficial data from the Ministry of Labor and Welfare put the number of immigrants in the working age group at 2.357.056 as of January 2005. These facts make the forecasts of doom coming out of standard demographic exercises hard to accept, and will require a more serious re-examination of the whole problem when better and more systematic data will become available.

One thing, in particular, we do not know is what the fertility rate is among immigrants and how it is evolving. Again, unsystematic evidence suggests much higher fertility rates among immigrants 
Table 2: The Spanish demographic scenario.

\begin{tabular}{rrrrrrrrrrr}
\hline \hline & \multicolumn{4}{c}{ Population structure } & SFI & \multicolumn{4}{c}{ Life expectancy } \\
& \multicolumn{4}{c}{ at 0 } & \multicolumn{3}{c}{ at 65} \\
\hline Year & Total & $0-14$ & $15-64$ & $65+$ & & M & F & M & F \\
& 000 's & $\%$ & $\%$ & $\%$ & & & & & \\
\hline 1950 & 27493 & 26.23 & 66.54 & 7.23 & - & 59.8 & 64.3 & 11.8 & 13.5 \\
1960 & 30070 & 27.30 & 64.20 & 8.40 & 2.86 & 67.4 & 72.2 & 12.5 & 14.3 \\
1970 & 34041 & 27.79 & 62.54 & 9.67 & 2.99 & 69.2 & 74.7 & 13.3 & 15.9 \\
1981 & 37683 & 25.70 & 63.06 & 11.24 & 2.20 & 70.4 & 16.2 & 13.6 & 16.4 \\
1991 & 38872 & 18.63 & 67.43 & 13.94 & 1.34 & 73.4 & 80.5 & 15.5 & 19.2 \\
1996 & 39670 & 15.81 & 68.54 & 15.65 & 1.16 & 74.3 & 81.6 & 16.0 & 20.1 \\
2000 & 40122 & 14.58 & 68.54 & 16.88 & 1.15 & 75.3 & 82.4 & 16.5 & 20.8 \\
2010 & 40359 & 13.13 & 68.73 & 18.14 & 1.22 & 76.8 & 83.8 & - & - \\
2020 & 43378 & 11.16 & 68.23 & 20.61 & 1.31 & 78.0 & 84.8 & - & - \\
\hline
\end{tabular}

Source: INE, www.fedea.es, and U.S. Bureau of the Census.

than among Spanish citizens, but what remains unclear is the speed at which the fertility patterns of the former will converge to those of the latter. As a matter of fact, Spanish fertility rates have fallen so rapidly and dramatically since 1977 that, in spite of the documented increase in life expectancy, forward projections of current trends (excluding immigration) forecast an important decline of the population by 2050. Under this fertility scenarios, Spanish population is projected to start declining by the year 2020. In 1965, the Spanish synthetic fertility index (SFI) reached the peak of its post civil war recovery, at almost 3.0 children per woman (well above the European average at the time). It remained relatively stable for more than a decade, until 1976, when it suddenly started declining to reach 1.16 in year 2000 (second lowest in Europe, after Italy). This amounts to a reduction of practically two children per woman in about a generation. In the last three years, the fertility rate of Spanish women has given signs of recovery, it currently stands at 1.35 , which is still very low by most standards and certainly unable to prevent the forecasted population decline.

This fertility reduction has been paralleled by an increase in both prime age female labor force participation and educational attainment of Spanish women; the latter change has been dramatic: only in 1981 the share of people older than 16 with a completed college degree was $6.4 \%$ for men and $4.5 \%$ for women, while in the 2001 Census those percentages are $13.2 \%$ and $13.9 \%$ respectively. In 1977 the fraction of 25 years old women with tertiary education was 6.4 percent, this fraction reached 24.6 percent in 1995 and 34.2 in 2000. During the same period (1977-95) the increase in the labor force participation rates (LFPR) of women 16-64 has been modest compared to most OECD countries (from 32.6 to 46.0 percent). Since 1995 the increase has accelerated and the participation rate of women has reached now 51.6 percent; given that it is already above 80.0 percent for women with tertiary education or higher, it is reasonable to forecast that it will keep increasing sharply for the next two decades or so. With regard to the LFPR of married women, the increase has been spectacular, from 21.4 percent in 1977 to 40.8 in 1995 and 46.6 percent in 2000. The figures for married adult women (25-54) are even higher: from 22.2 in 1977 to 54.5 in 2000. In summary, for prime age women (25-54), the LFPR (employment in brackets) between 1977 and 2000 has gone 
from 29.1 (28.6) per cent to 62.3 (50.6) per cent.

In the light of the very recent trends for SFI and immigration flows, then, the population projections mentioned earlier are likely to be biased downward. The immigration factor, in particular, cannot be ignored even in the short and medium run. Migration has always been an important demographic factor for Spain, but the sign of the flow has reversed: Spaniards are no longer emigrating, instead people, mostly from North Africa and Latin America but also from poorer Eastern European countries, are immigrating into Spain. However, and in spite of the substantial flow of illegal immigrants, that some estimate at around 350-400 thousands individuals a year, until the current year the Spanish socio-political environment did not appear ready to adopt policies favoring immigration and allowing a legalization of those already working in the country. After about ten years of legislative passivity, in front of a continuously mounting flow of illegal immigrants, this policy choice has very recently been reversed. The effects on the social security system will probably be rapidly visible.

The Spanish labor force survey (Encuesta de Población Activa, or EPA) provides an alternative source of data about Spanish immigration. While in 1977-1980 the fraction of people born abroad among those interviewed in EPA was 0.31 percent, in 1998-2000 this fraction had increased to above 1.00 percent; in the same years, the Social Security affiliation files suggested that foreigners represent about 3.0 percent of the legal workforce. While pointing in the correct direction, these are still substantial underestimates: our back of the envelope calculations suggest that foreign immigrants may account, as of 2005, for about 10 to $15 \%$ of the Spanish work force. Furthermore, while, in 1977-1980 the male labor force participation rate of people born abroad (64 percent) was well below the Spanish male average (74 per cent), in recent years, the situation has reversed and the labor force participation of men born abroad is 11 percentage points higher than that of Spaniards (74.1 against 63.0).

In the face of this data and of the rapidly mutating political approach foreign workers, taking a stance on the future evolution of immigration into Spain and of its impact on the Spanish labor force appears difficult. It is our belief, nevertheless, that the very recent trends are likely to be sustained and that the earlier forecasts of a decreasing population starting in 2020 are most likely to be contradicted.

\section{Background on the Spanish Social Security System}

\subsection{History}

Mandatory insurance for job related accidents was introduced in 1900, through a bill that also authorized the creation of some funds, for public employees only, paying disability and retirement pensions. In 1919, mandatory retirement insurance (Retiro Obrero Obligatorio) was introduced for private sector employees aged 16-65 whose total annual salary was below a certain threshold. In 1926, a universal pension system for public employees (Régimen de Clases Pasivas, or RCP) was established, which still exists under the same name. By the late 1930s, most Spanish employees were covered, in one form or another, by some minimal, government mandated retirement insurance program.

With the end of the Republic and the advent of Franco's regime, a number of changes were implemented. In 1939, Workers' Retirement (Retiro Obrero) was replaced by Old Age Insurance (Seguro de Vejez). While the former was based upon a capitalization system, the latter was from the beginning a completely unfunded pay-as-you-go scheme. By 1950, the system had acquired its basic organization in two pillars, which remained essentially unchanged until the mid 1970s. Public 
servants were all covered by the RCP, while private sector employees with annual earnings below a certain ceiling were covered by the Old Age Insurance. The 1963 reform created a very large number of special funds (Regimenes Especiales) next to the general scheme (Régimen General), generating a jungle of special treatments which is still being dismantled.

In 1977, a reform bill made a first attempt at harmonizing the many existing funds, by reducing the differences in the treatment they offered and by putting (in 1979) the administration of the whole system under the newly created National Social Security Institute (Instituto Nacional de la Seguridad Social, or INSS). Overall, this process increased the percentage of workers covered by the public SS system.

\subsection{Rules of the System}

\subsection{The 1985 Reform and the Current System}

The key rules before the 1985 reform (see Barrada (1999) for a complete description) were the following:

1. The Normal Retirement Age is set at 65 and the Early Retirement Age, for those that started contributing before 1967 , at 60 .

2. Elegibility: 10 years of contributions, of which 2 years should be in the last seven years preceding the date of retirement.

3. Amount of pension: $50 \%$ of the "benefit base" with 10 years of contributions, plus $2 \%$ for each additional year of contributions, up to $100 \%$ with 35 years.

The reform process, which came to shape the current regime, introduced a few important changes: Eligibility criteria for disability pensions were tightened; the minimum number of years of contributions required to obtain an old-age pension was increased from 8 to 15; and the number of years entering the computation of the benefit base was increased from 2 to 8 . On June 26, 1997, many of the parameters used for the computation of benefit bases and pensions were modified. The number of contributive years over which the benefit base is computed was increased from 8 to 15 (by year 2001). The formula for the computation of the replacement rate $\alpha$ (see below) was also made less generous, whereas the $8 \%$ per-year penalty applied to early retirees between the ages of 60 and 65 was reduced to $7 \%$ for those individuals with 40 or more contributive years at the time of retirement.

Currently, the Spanish Social Security offers two pathways to regular retirement ${ }^{3}$ : early retirement and normal retirement. Early retirement is possible starting at age 60, while the normal retirement age is 65, although some professional groups have lower normal retirement ages (miners, military personnel, policemen and fishermen are the main ones). Collective wage settlements often impose mandatory retirement at age 65 , facilitate retirement at 64 with full benefits, or encourage retirement between 60 and 63 through lump sum payments.

Public pensions are provided by the following programs.

- The "General Social Security Scheme" (Régimen General de la Seguridad Social, or RGSS) and the "Special Social Security Schemes for Self-employed" (Régimen Especial de Trabajadores Autónomos or RETA). They cover, respectively, the private sector employees and the

\footnotetext{
${ }^{3}$ That is to say, in the absence of disability or long term unemployment in late age.
} 
self-employed workers and professionals. The RGSS covers also the members of cooperative firms, the employees of most public administrations other than the central governments and all unemployed individuals complying with the minimum number of contributory years when reaching 65 .

- The scheme for government employees (Régimen de Clases Pasivas, or RCP) includes public servants employed by the central government and its local branches.

\subsection{Rules of the RGSS}

This subsection describes the rules governing, since 1985, the old-age and survivors pensions in the RGSS. The changes introduced by the 1997 reform (R97) and the 2002 (A02) amendment will be illustrated as we go along. A summary of the basic technical aspects of the pre- and post-1997 systems can be found in Table 3 .

\section{Financing and Eligibility}

The RGSS is a pure pay-as-you-go scheme. Contributions are a fixed proportion of covered earnings, defined as total earnings, excluding payments for overtime work, between a floor and a ceiling that vary by broadly defined professional categories. Currently, eleven categories are distinguished, each one with its own ceiling and floor for covered earnings. The current RGSS contribution rate is 28.3 percent, of which 23.6 percent is attributed to the employer and the remaining 4.7 percent to the employee. A tax rate of 14 percent is levied on earnings from overtime work.

Entitlement to an old-age pension requires at least 15 years of contributions. As a general rule, recipiency is conditional on having reached age 65 and is incompatible with income from any kind of employment requiring affiliation to the Social Security system.

\section{Benefit computation}

When eligibility conditions are met, a retiring worker receives an initial monthly pension $P_{t}$ equal to

$$
P_{t}=\alpha_{n} \mathrm{BR}_{t},
$$

where the benefit base (base reguladora) $\mathrm{BR}_{t}$ is a weighted average of covered monthly earnings over a reference period that consists of the last 8 years before retirement

$$
\mathrm{BR}_{t}=\frac{1}{112}\left(\sum_{j=1}^{24} W_{t-j}+\sum_{j=25}^{96} W_{t-j} \frac{I_{t-25}}{I_{t-j}}\right),
$$

where $W_{t-j}$ and $I_{t-j}$ are earnings and the consumer price index in the $j$-th month before retirement. Pensions are paid in fourteen annual installments, hence the division by 112 in the previous formula.

The replacement rate $\alpha_{n}$ depends on the age of the retirees and on the number of years of contribution. When age is below $60, \alpha_{n}=0$ for all $n$. For age equal or larger than $65, \alpha_{n}$ is equal to

$$
\alpha_{n}= \begin{cases}0, & \text { if } n<15, \\ .6+.02(n-15), & \text { if } 15 \leq n<35, \\ 1, & \text { if } 35 \leq n\end{cases}
$$


In the case of early retirement, i.e. for ages between 60 and $65, \alpha_{n}$ is determined by the previous formula multiplied a penalization factor. The latter is equal to .60 at 60 , and increases of .08 each year, until reaching the value of 1.0 at age 65 .

Beginning in 1997, the number of reference years used for computing $B R_{t}$ has been increased by one every year until 2003, to reach a total of 15 years. The formula for computing $\alpha_{n}$ has been changed to the following

$$
\alpha_{n}=\left\{\begin{array}{lll}
0, & \text { if } n<15, \\
.5+.03(n-15), & \text { if } 15 \leq n<25, \\
.8+.02(n-25), & \text { if } 25 \leq n<35 \\
1, & \text { if } 35 \leq n .
\end{array}\right.
$$

The penalization factors have, basically, remained the same, exception made for workers with 40 or more years of contributions (details in the next subsection).

The A02 amendment allows for the possibility of $\alpha_{n}$ being greater that one when people are above 65 years of age, that is

$$
\alpha_{n}=\{1+.02(a-65), \quad \text { if } \quad 65 \leq a \quad \text { and } n \geq 35,
$$

Outstanding pensions are fully indexed to price inflation, as measured by the consumer price index. Until 1986, pensions were also indexed to real wage growth.

\section{Early retirement}

The normal retirement age is 65 but early retirement at age 60 is permitted under fairly common circumstances. The replacement rate for early retirees is reduced by 8 percentage points for each year under age 65 . Starting from 1997, workers who retires after the age of 60 with 40 or more contributive years are charged a penalty of only 7 percent for each year under age 65 . The 2002 amendment has modified further the rules determining the replacement rate. It now reads as follows

$$
\alpha_{n}= \begin{cases}0, & \text { if } \quad a<61 \\ 1-\kappa(a-60), & \text { if } \quad 61 \leq a<65 \\ 1, & \text { if } \quad 65 \leq a\end{cases}
$$

where,

$$
\kappa=\left\{\begin{array}{lll}
0.08 & \text { if } \quad n=30, \\
0.075 & \text { if } \quad 31 \leq n \leq 34, \\
0.07 & \text { if } \quad 35 \leq n \leq<37, \\
0.065 & \text { if } \quad 38 \leq n \leq<39, \\
0.06 & \text { if } \quad 40 \leq n .
\end{array}\right.
$$

Unless a collective labor agreement prescribes mandatory retirement, individuals may continue working after age 65 . Before 2002 there were no incentives to work past age 65 . As mentioned, the 2002 legislation now allows for

$$
\alpha_{n}=\{1+.02(a-65), \quad \text { if } \quad 65 \leq a \quad \text { and } \quad n \geq 35,
$$


and eliminates social security contributions for workers meeting the eligibility criteria for full normal retirement ( $a \geq 65$ and $n \geq 35$ ) and who continue working. About ten percent of the workers enrolled in the RGSS is actually exempt from reduction in the replacement rate in case of early retirement.

\section{Maximum and minimum pension}

Pensions are subject to a ceiling, legislated annually and roughly equal to the ceiling on covered earnings. The 2000 ceiling corresponds to about 4.3 times the minimum wage (salario minimo interprofesional, or SMI) and about 1.6 times the average monthly earnings in the manufacturing and service sectors. If the initial old-age pension, computed as above, is below a minimum, then the minimum pension is paid. The latter is also legislated annually. Other things being equal, minimum pensions are higher for those who are older than 65 or have a dependent spouse.

In the last decade, minimum pensions grew at about the same rate as nominal wages, whereas maximum pensions grew at the rate of inflation. The ratio between the minimum old-age pension and the minimum wage has been increasing steadily from the late 1970s (it was 75 percent in 1975) until reaching almost 100 percent in the early 1990s. The percentage of RGSS retirees receiving a minimum pension has been declining steadily, from over 75 percent in the late 1970s to 27 percent in 1995 .

\section{Family considerations}

A pensioner receives a fixed annual allowance for each dependent child that is younger than 18 or disabled. In 2000, this allowance was equal to 48,420 pesetas (or 291 euros) for each child under 18 , and to 468,720 pesetas (2817 euros or 45 percent of the annualized minimum wage) for each disabled child.

Survivors (spouse, children, other relatives) may receive a fraction of the benefit base of the deceased if the latter was a pensioner or died before retirement after contributing for at least 500 days in the last 5 years. The surviving spouse gets 45 percent of the benefit base of the deceased (46 percent after the 2002 amendment, fraction that will be increased further in the forthcoming years). Such pension is compatible with labor income and any other old-age or disability pension, but is lost if the spouse marries anew. Each of the surviving children gets 20 percent of the benefit base until the age of 18 (amount raised to 23 per cent in 1997). An orphan who is the sole beneficiary may receive up to 65 percent of the benefit base. If there are several surviving children, the sum of the pensions to the surviving spouse (if any) and the children cannot exceed 100 percent of the benefit base.

A Spanish peculiarity is the "pension in favor of family members". This pension entitles other surviving relatives (e.g. parents, grandparents, siblings, nephews, etc.) to 20 percent of the benefit base of the principal if they satisfy certain eligibility conditions (older than 45, do not have a spouse, do not have other means of subsistence, have been living with and depending economically upon the deceased for the last two years). To this pension, one may add the 45 percent survivors pension if there is no surviving spouse or eligible surviving children.

\section{Rules for the self-employed}

In this section we sketch the main differences between the RGSS and the RETA. Beside differences in the SS tax rate and the definition of covered earnings, the people affiliated to RETA and who are not miners or sailors have no early retirement option . 
While the SS tax rate is the same for the RETA and the general scheme (28.3 percent in 2000), covered earnings are computed differently, as the self-employed are essentially free to choose their covered earnings between a floor and a ceiling legislated annually. Not surprisingly in the light of the strong progressivity of Spanish personal income taxes, a suspiciously large proportion of self-employed workers report earnings equal to the legislated floor until they reach about age 50 to 55. After that age one observes a sudden increase in reported covered earnings. This behavior exploits the "finite memory" in the formula for the calculation of the initial pension and appears to be fading after the 1997 legislation increased the number of years used in that calculation from eight to fifteen.

A crucial difference with respect to the general scheme is that, under the RETA, recipiency of an old-age pension is compatible with maintaining the self-employed status. Other important provisions are the following: RETA only requires 5 years of contributions in the 10 years immediately before the death of the principal in order to qualify for survivors pensions. Under RETA, the latter is 50 percent of the benefit base. If the principal was not a pensioner at the time of death, the benefit base is computed as the average of covered earnings over an uninterrupted period of 5 years chosen by the beneficiary among the last 10 years before the death of the principal.

\section{Rules for central government employees (RCP)}

We now describe briefly the main differences between the general scheme and the RCP, the pension fund for the employees of the central government. Public servants are divided into 5 categories, labelled from A to E, corresponding loosely to decreasing school levels: A for college graduates, B for people holding certain kinds of college diplomas, C for high school graduates, D for junior high school diplomas, and $\mathrm{E}$ for individuals with lower education levels. For each of these categories, the budget law defines every year a theoretical SS wage, which is used to compute SS contributions and pensions. The implied wage scale has remained relatively constant since 1985 . The top to bottom ratio never exceeded 2.5.

The basic monthly pension of a public servant who retires in month $t$ after contributing for $n$ years to RCP is computed as $P_{t}=\alpha_{n} \mathrm{BR}_{t}$, where the dependence of $\alpha_{n}$ upon the numbers of years worked has changed frequently over time. For $n \geq 15$, the last table of proportionality factors, legislated in 1990, can be reasonably (but not exactly) approximated by

$$
\alpha_{n}=\min (1,1-.0366(35-n)) .
$$

The differences with respect to the general scheme are various. First, while the entitlement to a pension still requires at least 15 years of contributions, the replacement rate (the ratio of the pension to the benefit base) increases somewhat irregularly with seniority, up to 100 percent after 35 years. So, for example, 15 years of service give right to a pension equal to only 26.92 percent of the benefit base, against 60 percent of the general scheme. After 30 years the same ratio has increased to 81.73 percent, against 90 percent for the general scheme.

Second, the benefit base is computed as a weighted average of covered earnings upon which the worker paid the contributions, with weights equal to the percentage of the career spent at each level, that is,

$$
\mathrm{BR}_{t}=\sum_{i} p_{i} H_{i t}
$$

where $p_{i}$ is the fraction of the career spent on level $i$ and $H_{i t}$ are the covered earnings corresponding to level $i$, as determined by the current law at time $t$. 
Table 3: Pension provisions, institutions and systems

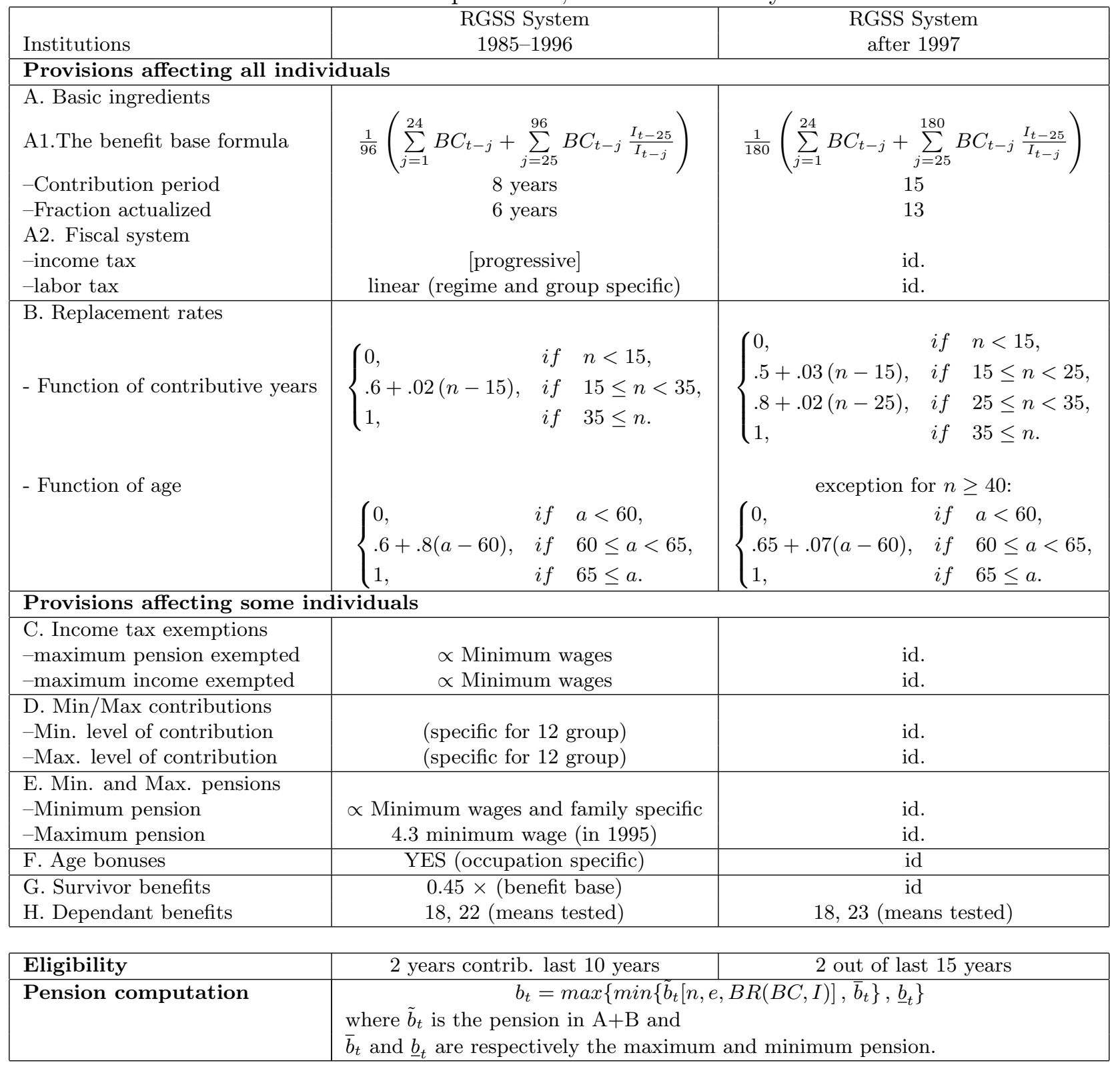

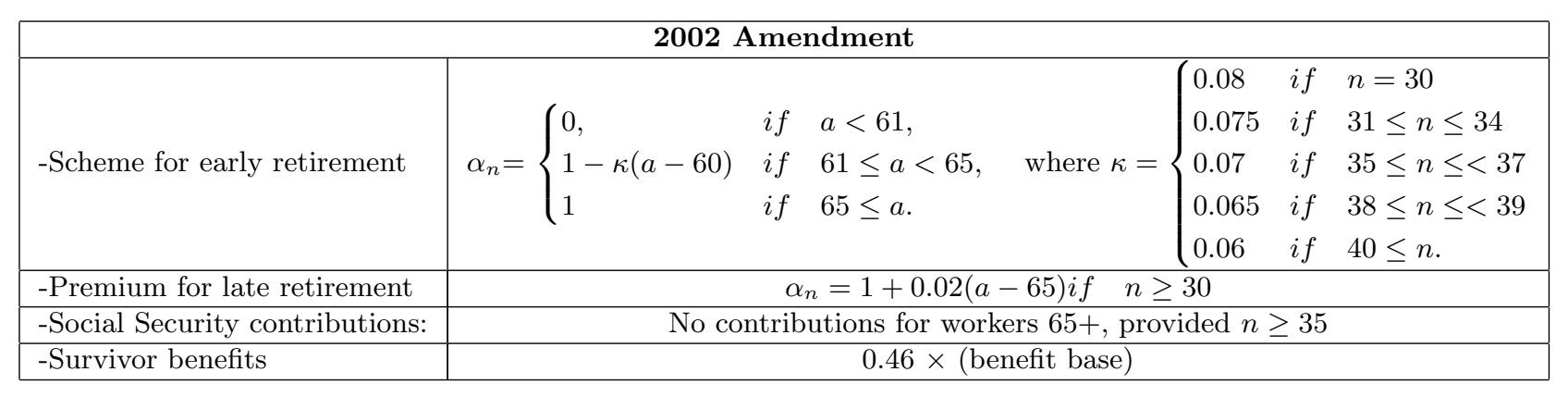


Third, unlike the general scheme, the RCP imposes mandatory retirement at age 65. Exception are made for a few special categories, such as university professors and judges. On the other hand, the RCP allows for early retirement at the age of 60 , without any penalty for public servants with at least 30 years of service (20 for military personnel).

A fourth important difference with respect to the general scheme is compatibility between RCP pensions recipiency and income from continuing to work. In a number of special cases, RCP pensioners are allowed to keep a public sector occupation, as long as this does not provide them with a "regular flow of income" (for example, this is the case of members of legislative bodies). More importantly, the legislation allows RCP pensions to be cumulated with earnings from employment in the private sector.

\section{Description of Data and sources}

We start by providing an index of the data set that are currently available. One important limitation should be noticed: there is no single data set covering the whole period 1975-2005. Most time series, therefore, will be constructed by splining data from different sources, creating obvious problems of consistency, which, while less dramatic than one might expect, are nevertheless substantial.

- Income data. We draw information about the level, distribution and sources of income from four micro data sources

1. The European Community Household Panel (ECHP), a longitudinal survey covering 7000 households during 1994-2001

2. The Encuesta Continua de Presupuestos Familiares 1985 (ECPF 85), a rotating panel of 3000 households, covering the period 1985-1996.

3. The Encuesta Continua de Presupuestos Familiares 1997 (ECPF 97), a rotating panel of 8000 households, from 1997 to the current days.

4. A set of historical data on individual pensions, from the archives of the Spanish Social Security Administration, covering about 250 thousands workers and pensioners during the decade 1988-1998 (HLSS 1998; see Boldrin et al (2004) for more details).

- Consumption and household's income. We have access to three sets of microeconomic data containing information about individual and households' consumption.

1. The Encuesta Continua de Presupuestos Familiares 1985 (ECPF 85), a rotating panel of 3000 households, covering the period 1985-1996.

2. The Encuesta Continua de Presupuestos Familiares 1997 (ECPF 97), a rotating panel of 8000 households, from 1997 to the current days.

3. The Encuesta de Presupuestos Familiares (EPF), a cross-sectional survey carried out during the years 1973-1974, 1980-1981 and 1990-1991, over sample of households of varying magnitudes (the largest one, 1990-1991, covered about 21,500 households for a total of about 77,000 individuals).

- Employment. Data about employment and labor force participation come from the Encuesta de Población Activa(EPA), a rotating quarterly panel survey started in 1976 and continuing to these days. 
Table 4: Variables and Data Sources

\begin{tabular}{lrrrr}
\hline \hline Measure & Source & Period & Ages & Obs. (000s) \\
\hline Benefits & HLSS & 1998 & all ages & 85 \\
Income & EPF & $80-81$ & $60-75+$ & 107 \\
Income & ECPF & $85-97$ & $60-75+$ & 247 \\
Income & ECHP & $94-01$ & $60-75+$ & 123 \\
Consumption & EPF & $80-81$ & $60-75+$ & 107 \\
Consumption $_{\text {Consumption }}{ }^{a}$ & ECPF & $85-97$ & $60-75+$ & 247 \\
Life satisfaction $_{\text {ECPF }}$ & EB & $97-01$ & $60-75+$ & +400 \\
Health Status & ES & $85-87,93$ & $60-75+$ & 17 \\
Health Status & ECHP & $94-01$ & $60-75+$ & 123.1 \\
\hline
\end{tabular}

- Life Satisfaction. Few sources of information are available here, none highly reliable or based upon an extensive sample. We use the answers to a few specific questions in small and irregular sociological surveys carried out by CIS and by Eurobarometer (EB) during the period 1985-2002.

- Health Status. Information about health status comes from three different sources.

1. The ECHP contains a few variables measuring both health status and personal usage of health care services.

2. The Encuestas de Salud (ES) carried out in 1985-1987, 1989, 1993, 1995, 1999, and 2001.

3. The Disability, Impairment and Health Status Survey (DIHSS), which was carried out in 1999, and covered 79,000 households for a total of 220,000 people.

- Wealth. We have no reliable sources of data about wealth distribution and its composition at the individual or household levels. In recent years, the Bank of Spain has launched a survey to study consumer's finances. However it does not overlap with our period of study.

The information about data availability, sources, and period of time covered is summarized in Table 4

\section{Well-Being of the elderly over time}

\subsection{Income and Consumption Measures}

The first set of questions we ask is concerned with the income of the elderly, its level, sources, distribution, and dynamics in relation to that of the average national income. To provide a benchmark against which to evaluate performances we present first some evidence relative to the whole population. Table 5 reports, from various and not homogeneous sources, a number of measures of earning and consumption expenditure. For each variable we report both per capita and household averages; the variable considered are, from left to right, food expenditure, total consumption expenditure, and total earnings; the last column reports the average household size. Three sources of data are used, the EPF 73-74 and 80-81 and the ECPF 85, which explains the discontinuities 
Table 5: Income and consumption expenditure. 2002 Euros

\begin{tabular}{lrrrrrrr}
\hline \hline & \multicolumn{2}{c}{ Food } & \multicolumn{2}{c}{ Total Cons. } & \multicolumn{2}{c}{ Earnings } & Family \\
Year & per capita & OECD scale & per capita & OECD scale & per capita & OECD scale & size \\
\hline 73 & 1679.60 & 2307.26 & 4834.67 & 6641.37 & 3995.94 & 5489.21 & 3.73 \\
81 & 1420.79 & 1953.38 & 4730.15 & 6503.28 & 4133.95 & 5683.59 & 3.70 \\
85 & 913.07 & 1239.23 & 4950.23 & 6718.55 & 4081.43 & 5539.39 & 3.65 \\
86 & 899.96 & 1217.36 & 4788.70 & 6477.60 & 4102.30 & 5549.12 & 3.59 \\
87 & 954.66 & 1284.02 & 5138.60 & 6911.43 & 4358.56 & 5862.28 & 3.55 \\
88 & 896.39 & 1203.23 & 5135.04 & 6892.82 & 4609.43 & 6187.29 & 3.52 \\
89 & 915.98 & 1227.26 & 5475.40 & 7336.12 & 4944.44 & 6624.72 & 3.51 \\
90 & 942.72 & 1255.32 & 5816.09 & 7744.73 & 5303.33 & 7061.94 & 3.42 \\
91 & 915.47 & 1213.84 & 6046.21 & 8016.81 & 5579.07 & 7397.41 & 3.39 \\
92 & 921.37 & 1216.58 & 6314.55 & 8337.72 & 5843.66 & 7715.95 & 3.31 \\
93 & 878.07 & 1157.43 & 6368.98 & 8395.28 & 5987.34 & 7892.23 & 3.25 \\
94 & 886.71 & 1168.06 & 6370.27 & 8391.50 & 5951.37 & 7839.68 & 3.26 \\
95 & 875.98 & 1151.88 & 6259.68 & 8231.24 & 6020.09 & 7916.19 & 3.26 \\
96 & 875.49 & 1148.12 & 6153.61 & 8069.88 & 6060.37 & 7947.60 & 3.22 \\
97 & & & & & & & \\
$98^{*}$ & 1159.76 & 1517.66 & 6184.16 & 8092.59 & - & & 3.24 \\
$99^{*}$ & 1157.99 & 1508.03 & 6385.71 & 8316.07 & - & & 3.16 \\
$00^{*}$ & 1220.07 & 1583.55 & 6838.07 & 8875.22 & - & & 3.09 \\
$01 *$ & 1249.03 & 1617.15 & 7071.15 & 9155.14 & - & & 3.03 \\
$02^{*}$ & 1243.00 & 1605.60 & 6985.08 & 9022.92 & - & & 3.00 \\
\hline Sources: & EPF $73-74,80-81 ;$ ECPF $85-02$ & & & &
\end{tabular}

Sources: EPF 73-74, 80-81; ECPF 85-02

in the reported levels of food expenditure between 1981 and 1985, and 1996 and 1998. Leaving this aside, and ignoring the amusing fact that in Spain reported income is always and substantially lower than reported consumption expenditure, two facts should be appreciated: the drop in average household size from almost 4 individuals in 1973 to 3 in 2002, and the close to $40 \%$ increase in real per capita consumption expenditure over the 1985-2002 period. This number looks surprisingly large when compared to the average growth rate of per capita real earnings over the same period (Table 1), which is barely at one percent per year.

Did Spanish pensions keep up with the growth in real personal earnings of the population at large? Figure 2 reports the behavior of per capita real benefits during 1980-2000, both in absolute value and in relation to mean income, for men and women respectively. Benefits have grown dramatically in relation to mean income, from 34 to about $60-65$ percent in just twenty years, while real per capita benefits more than doubled during the period. Notice that, both in absolute value and in relation to mean income, the two ratios are practically identical; interestingly: the one for males was lower than the one for females in 1980, when one would have expected the opposite in the light of the shorter working lifes of women. The evolution since 1995 is interesting, as it suggests that a substantial part of the flattening of the pension expenditure to GDP ratio we illustrated earlier on, is attributable to a growth rate of benefits lower than the growth rate of per capita national income. The drop in the ratio of benefits to mean income appears to be stronger for women. Overall the figure suggests an extremely rapid growth in per capita pension benefits until year 1997, after which pension benefits still grow but at a much lower pace than wages and earnings.

Social security benefits make up for the bulk of personal income among Spanish people aged 60 years or more, as Figure 3 illustrates; very little is left, especially after the age of 65 , for labor earnings and capital income. 
Figure 2: Absolute and relative trend of SS benefits by gender in 2002 euros.
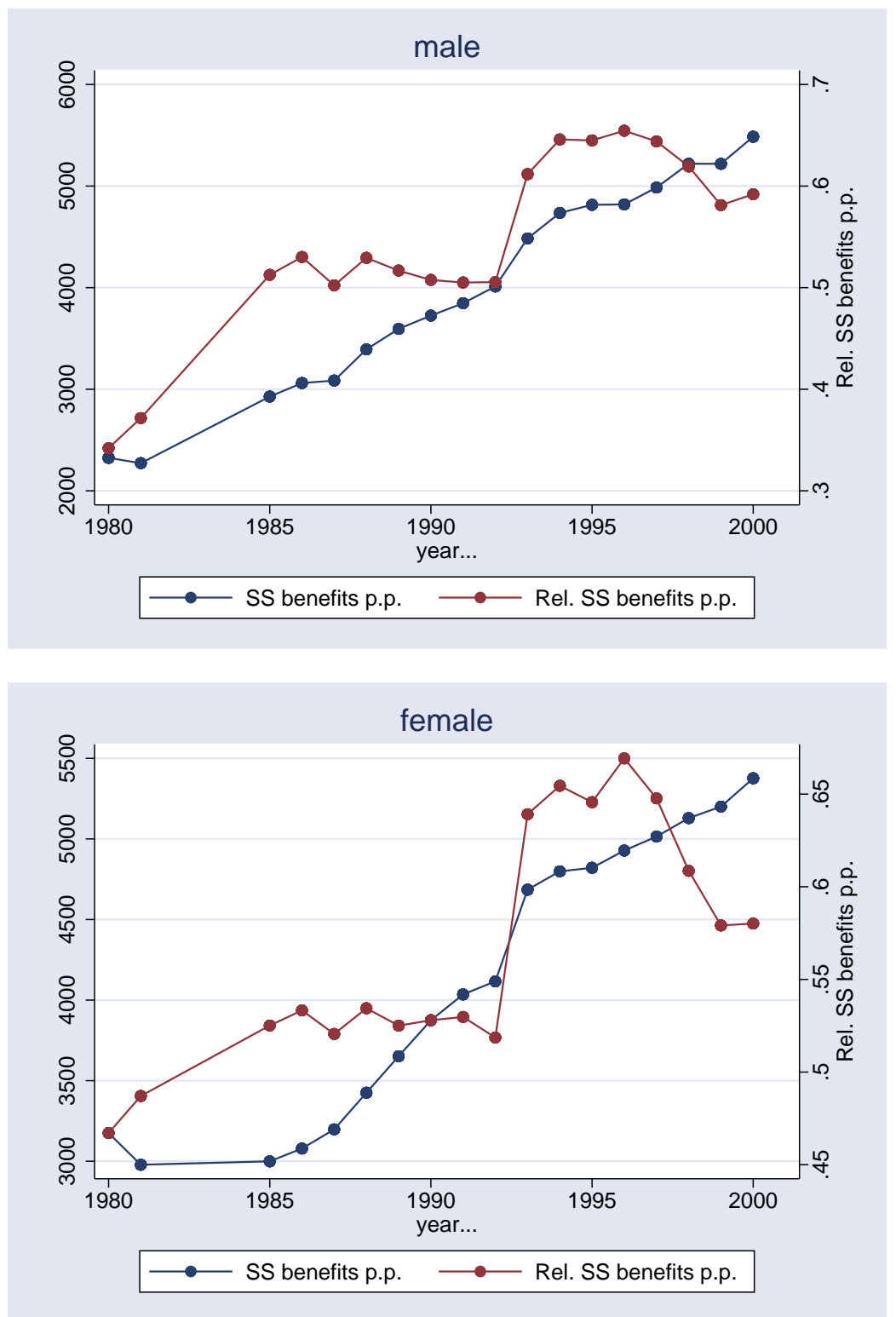
Figure 3: Distribution of personal income sources by sex and age group. source: ECHP.
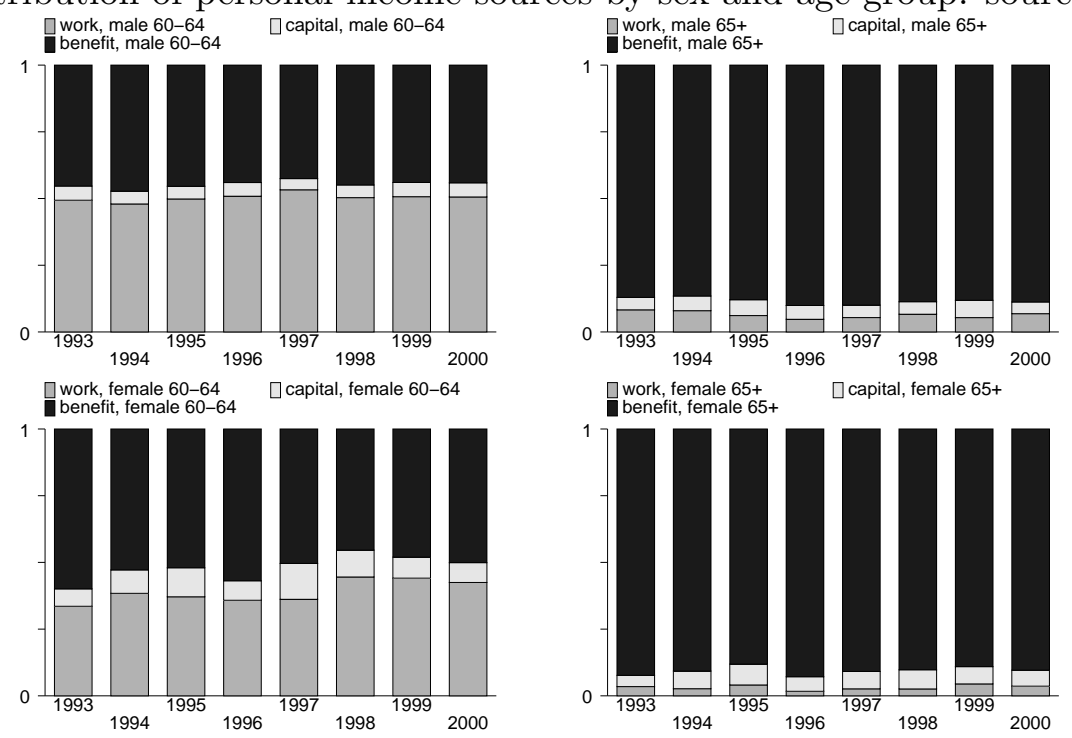

The same is true also when households are taken as units of measurement, as shown in Figure 4. Looking at this data and at the labor force participation rates of the elderly (see figure 5) one cannot resist speculating that the continuous increase (and then stagnation) in the ratio between pension benefits and average income reported in Figure 2 may have been the main driving force behind the reduction in the level of employment of Spanish people 60+, and its very recent, and very small, rebound. The four panels show that labor force participation and employment declined steadily and dramatically until 1997-1998, at which point the trend reversed. The reversal is clearly due to a change in the patterns of early retirement (60 to 64) as the two top panels show. The remarkable correlation between the behavior of the LFPR for this age group and the behavior of (approximately) the replacement ratio reported in Figure 2 suggest that some form of causation is most certainly at work here even if one should not underplay the "retention" role that the particularly buoyant labor market of the 1996-2004 period may have played in keeping older people from retirement. Either way, these figures are a dramatic proof that the labor supply of the elderly is not as inelastic as many assume, and that the employment rate of people older than 60 increase when their market wages increase faster than the retirement benefits.

To further assess the level and time trend of the initial replacement rate for perspective retirees, Figure 6 reports the average initial pension (in real Euros of year 2002) for the three main categories of retirees. The source of the data used here and in Figure 7 is the HLSS 98 sample, which is drawn in an unbalanced form from the SS benefits file. The overall increasing trend is clearly visible, even if the wide swing in the initial relative pension of people retiring at 60 requires explanation (see below). The average annual growth rate of the initial pension at 65 during the 1980-1998 period is equal to 2.3 percent, which is twice the growth rate of real earnings over the 1980-2000 period (see Table 1). In other words, the real value of initial pensions has increased by more than 60 percent in 20 years. The drop in the real value of initial pensions for the early retirees group, which is visible during the 1985-1990 period, is most likely attributable to the change in the benefit base formula (increased from 2 to 8 years) and the extraordinary use made during those years of the early retirement provision as an extension of unemployment insurance for old workers. A large number of old workers from restructuring firms were retired during those years by means of special 
Figure 4: Share of SS benefits in household, by age of head of household. 2002 euros.



Figure 5: Trend in participation and employment rates of the elderly 1977-2003 by gender and age group.
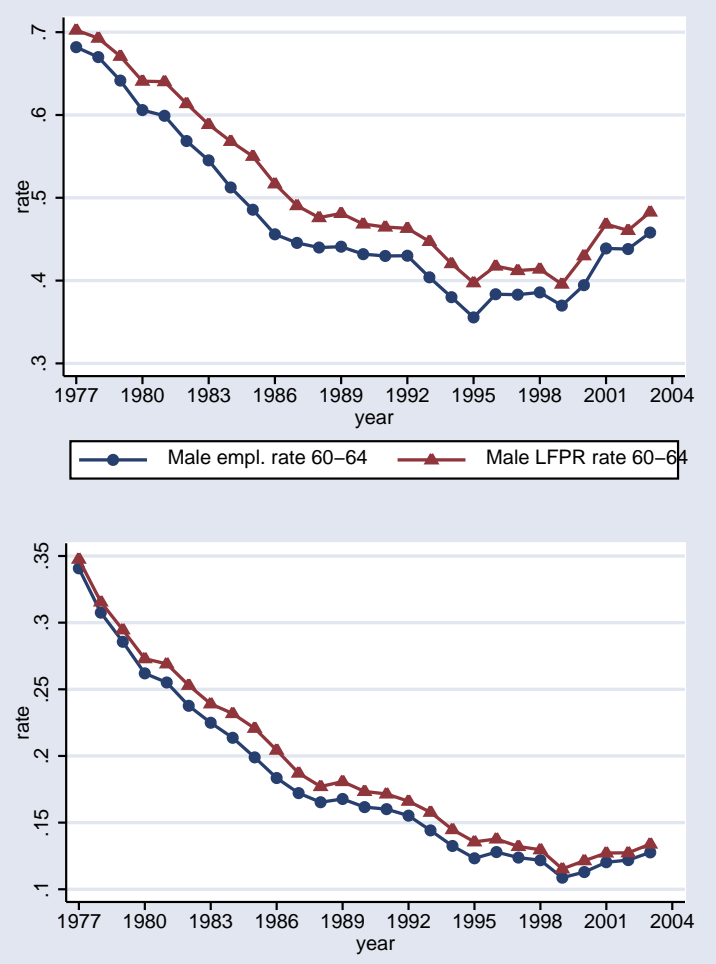

$\longrightarrow$ Male empl. rate 60+ $\longrightarrow$ Male LFPR rate 60+
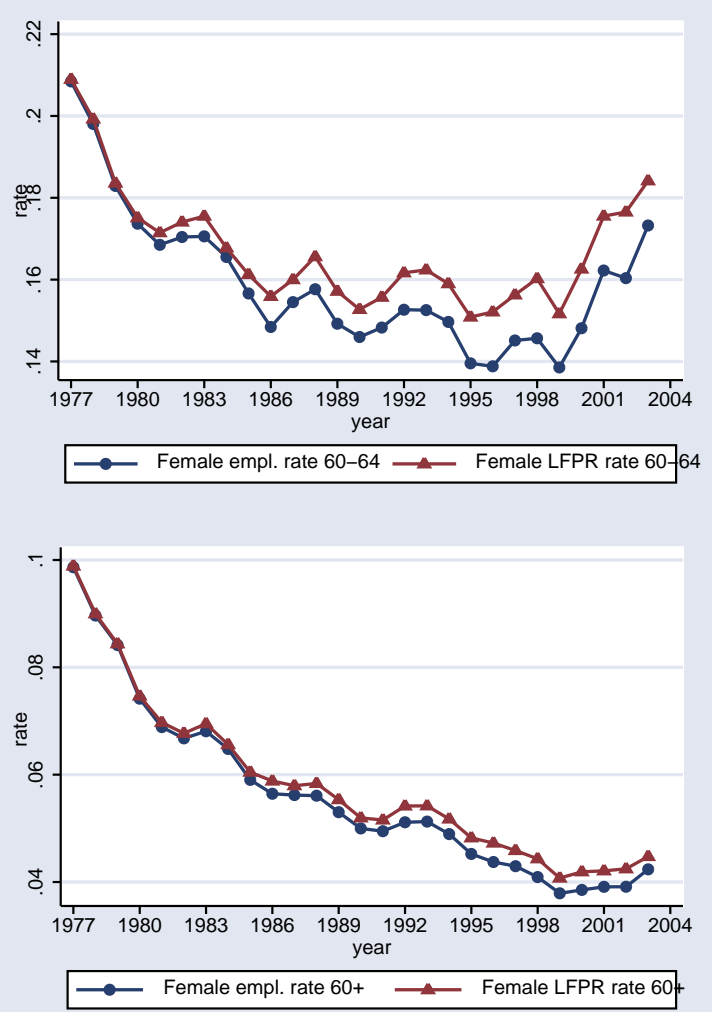
Figure 6: Average initial retirement pension at 60 and 65, and average initial disability pension relative to wages.

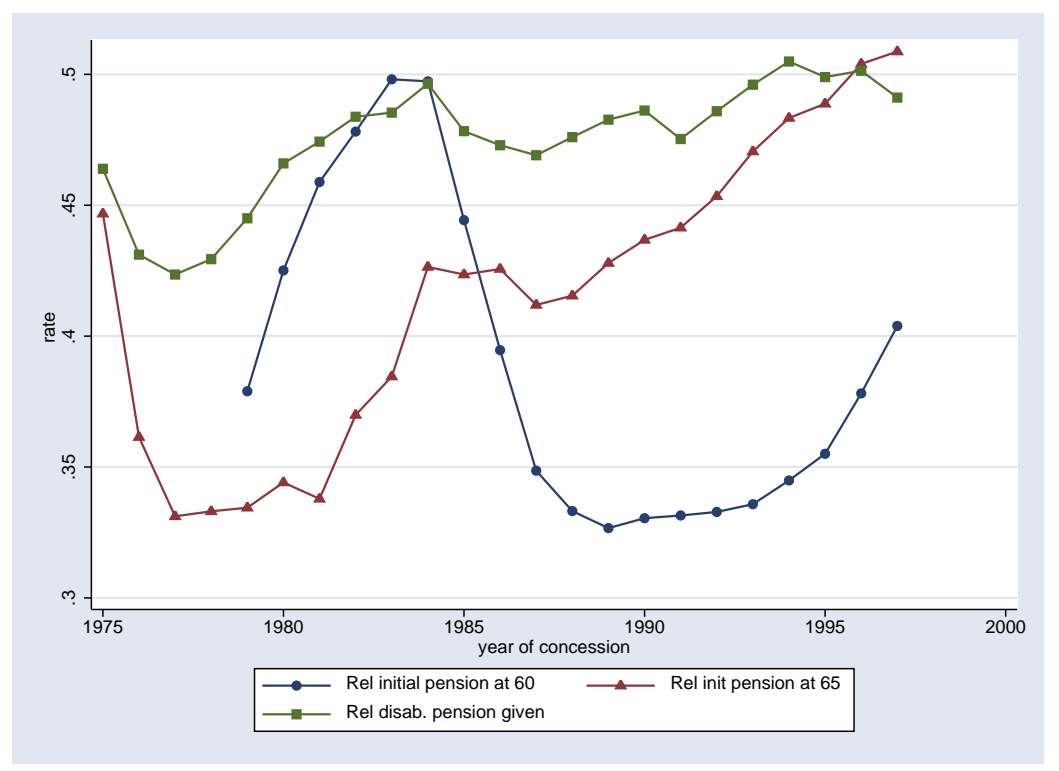

legal provisions, which included front-loaded cash payments to compensate for the relatively small (often: minimum) pension they would be receiving due to the early retirement mechanism. The 1975-1977 drop appears, instead, more as a sample bias or a reporting mistake. In Figure 6 we look at the extent to which gender differences in wages are translated into gender differences in the average pensions. Notice also here the two large swings, which are much more pronounced for males than females. This data is also from the HLSS 1998 files, and the anomalous oscillations it displays are worthy of further investigation. Finally, Figure 8 reports the average annual real revalorization by gender, showing that the initial bias in favor of women has been corrected in more recent years.

Next we look at a particularly important instrument of the Spanish social security system, the minimum pension. During the late 1970s and early 1980s, close to 70 percent of the Spanish pensioners received a minimum pension; in 2001 this percentage was still a very sizeable 32 percent of the stock of pensioners, with about 25 percent of new recipients starting out on a minimum pension. As Figure 7 shows, the minimum pension has grown substantially during the last fifteen years while the minimum wage has kept constant or even decreased, so much so that since year 2000 the minimum pension is higher than the minimum wage. The minimum pension has played a very important role during the years 1975-2000 to sustain and improve the living conditions of the bottom half of the Spanish elderly.

Averages, nevertheless, may notoriously hide substantial discrepancies, hence the following Table 6 tries to measure the extent to which conditions of relative "poverty", variously defined, have become more or less common in the Spanish society during the same interval of time. Specifically, we look here at the fraction of Spanish households that is below a certain per capita income or consumption level, where this is defined to be equal to either $25 \%$ or $40 \%$ of the median income or consumption among Spaniards that have less than 60 years of age. The overall impression is in line with the previous optimistic assessment: the percentage of households below either of the 
Figure 7: Ratio of average pension to average wage, by gender.

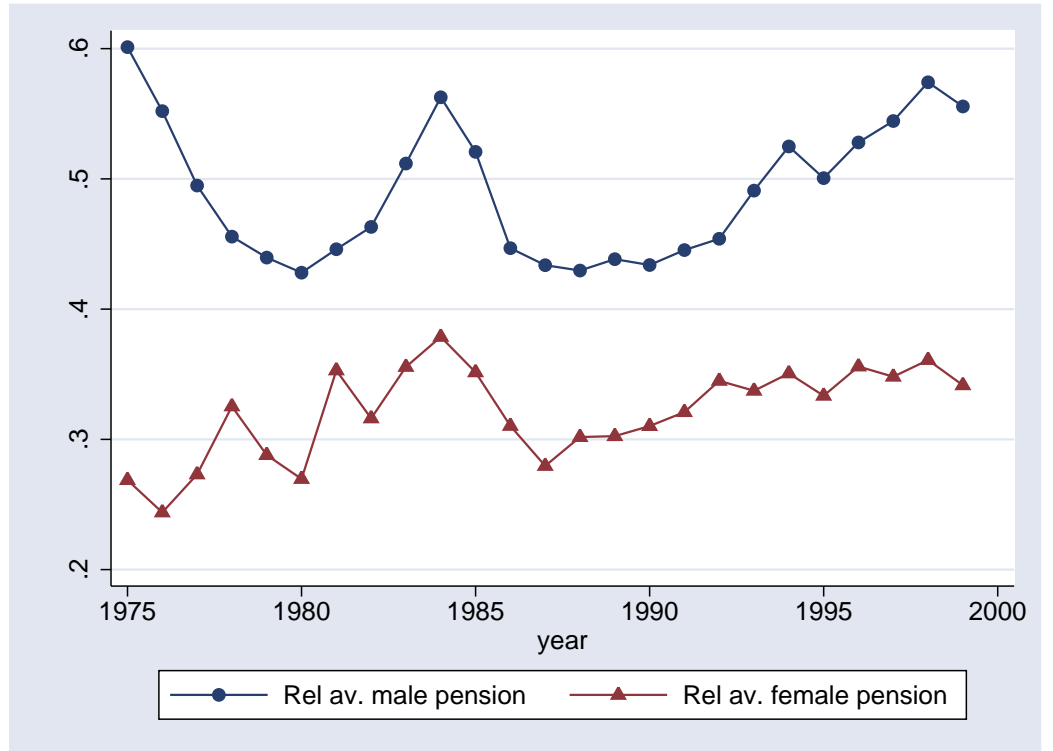

Figure 8: Average annual real revalorization by gender.

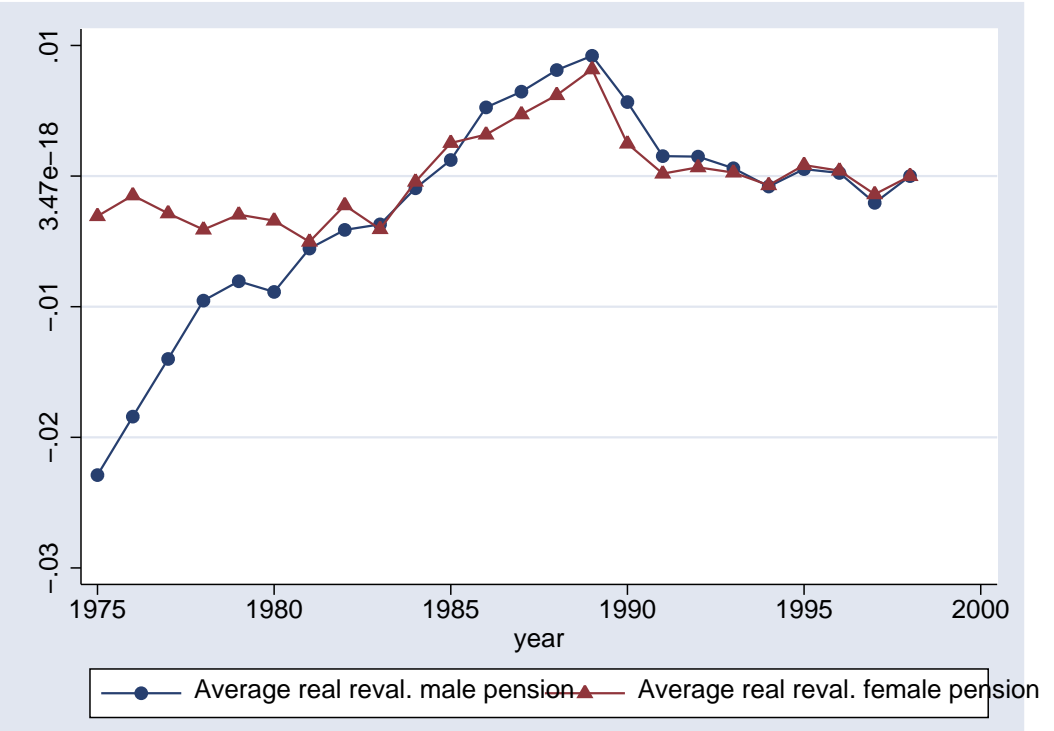

note: The average real revalorization (a) is computed as: $a=\exp \left(\frac{\log \left(P_{t}\right)-\log \left(I P_{\tau}\right)}{T-\tau}\right)-1$, where $P_{t}$ is the real pension in year $1999, I P_{\tau}$ is the real pension given at the year of retirement $\tau$, and $T-\tau$ is the number of years passed between the current and the year of retirement. 
Figure 9: Trends of minimum pension and minimum wage.

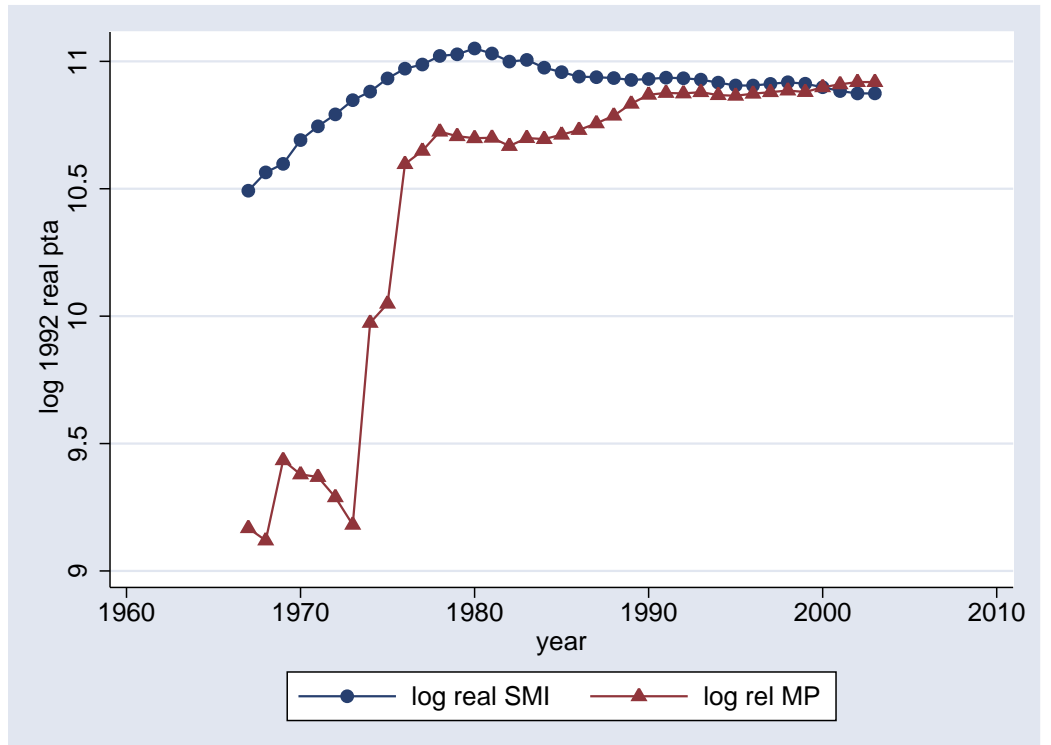

two threshold lines is very small to start with, and rapidly and monotonically decreasing over time. Extreme poverty (i.e. individuals below the $25 \%$ line) is practically negligible from a statistical point of view, while poverty seems to be restricted to no more than $4-5 \%$ of the total number of households.

To complete the overall survey of consumption and income measures, we report in Figures 10 to 18 the time trends of a few other measures of wellbeing: average social security benefits, per capita income among elderly and non, relative and absolute ${ }^{4}$ poverty indexes among the elderly. In each case the variable is computed and reported separately for two groups of individuals: those aged $60+$ and and those aged 60-. For each measure we report both the absolute level and an index, which is set at 100 in the first year of the sample period.

In the appendix our measures of per capita income and consumption are disaggregated further to investigate the extent to which the presence/absence of a retired or elderly person in a household affects income and consumption levels, and in which direction.

\subsection{Measures of Health and Quality of Life}

Objective measures point unanimously to a progressive and substantial improvement in the living conditions of the average Spaniard since 1970, and of the average elderly in particular. To complete the picture we report summary statistics describing subjective measures of welfare, in particular assessment of own life satisfaction and health, as well as some elementary objective measures of the latter. To compare the level of well being of elderly people to that of the average citizen, we report separately measures of the self-assessed quality of life for the whole population and for people aged 55 or more.

Feelings of mediocrity have apparently been pervading the Spanish society since the early 1980s, as the percentage of both those who declare themselves highly satisfied and those who declare themselves not at all satisfied have been decreasing almost steadily. The tendency seems common

\footnotetext{
${ }^{4}$ The absolute poverty line corresponds to an income below $40 \%$ of the median 1985 income for the non-elderly.
} 
Table 6: Fraction of all households below poverty lines (PL).

\begin{tabular}{lrrrrrrrr}
\hline \hline & \multicolumn{3}{c}{ Consumption } & \multicolumn{5}{c}{ Income } \\
\hline year & \multicolumn{2}{c}{ Per capita } & \multicolumn{2}{c}{ OECD scale } & \multicolumn{2}{c}{ Per capita } & OECD scale \\
& $25 \%$ PL & $40 \%$ PL & $25 \%$ PL & $40 \%$ PL & $25 \%$ PL & $40 \%$ PL & $25 \%$ PL & $40 \%$ PL \\
73 & 0.014 & 0.075 & 0.019 & 0.082 & 0.016 & 0.070 & 0.016 & 0.072 \\
81 & 0.014 & 0.065 & 0.020 & 0.079 & 0.013 & 0.050 & 0.014 & 0.054 \\
85 & 0.013 & 0.061 & 0.013 & 0.072 & 0.022 & 0.067 & 0.023 & 0.070 \\
86 & 0.012 & 0.064 & 0.011 & 0.073 & 0.021 & 0.049 & 0.022 & 0.053 \\
87 & 0.010 & 0.053 & 0.010 & 0.064 & 0.017 & 0.041 & 0.016 & 0.044 \\
88 & 0.009 & 0.046 & 0.009 & 0.058 & 0.016 & 0.038 & 0.015 & 0.040 \\
89 & 0.007 & 0.045 & 0.008 & 0.062 & 0.006 & 0.035 & 0.006 & 0.034 \\
90 & 0.007 & 0.045 & 0.010 & 0.058 & 0.009 & 0.037 & 0.010 & 0.039 \\
91 & 0.008 & 0.048 & 0.011 & 0.059 & 0.013 & 0.043 & 0.013 & 0.044 \\
92 & 0.005 & 0.040 & 0.008 & 0.059 & 0.008 & 0.032 & 0.010 & 0.037 \\
93 & 0.006 & 0.041 & 0.008 & 0.056 & 0.011 & 0.034 & 0.012 & 0.038 \\
94 & 0.007 & 0.048 & 0.009 & 0.055 & 0.011 & 0.042 & 0.011 & 0.040 \\
95 & 0.006 & 0.047 & 0.006 & 0.051 & 0.010 & 0.046 & 0.009 & 0.043 \\
96 & 0.006 & 0.038 & 0.007 & 0.046 & 0.016 & 0.048 & 0.013 & 0.047 \\
\hline
\end{tabular}

Figure 10: Trend of SS benefits (oecd standarized).

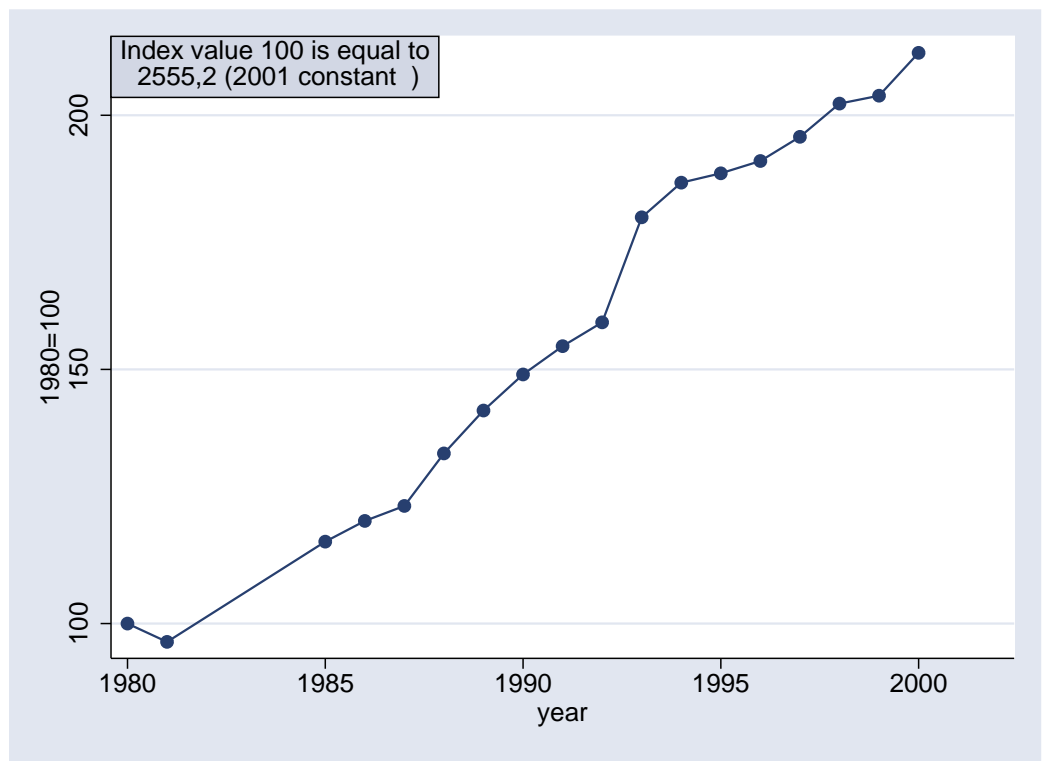


Figure 11: Trend of income (OECD standarized).

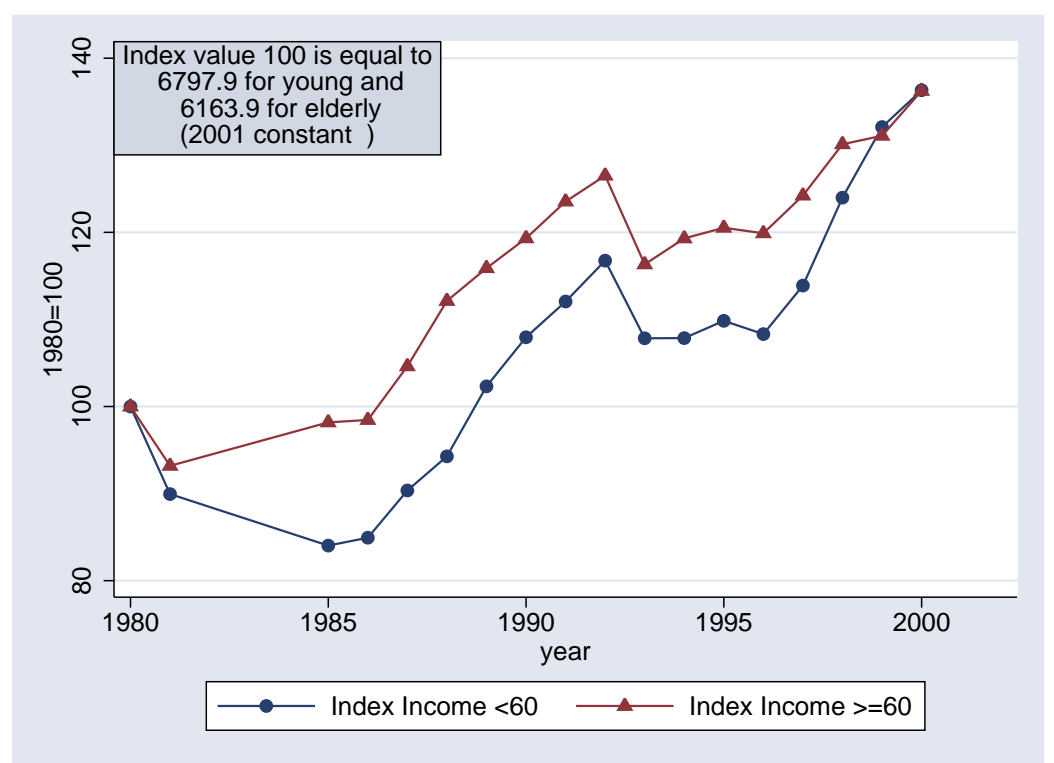

Figure 12: Trend of relative poverty (40\% of median non-elderly income).

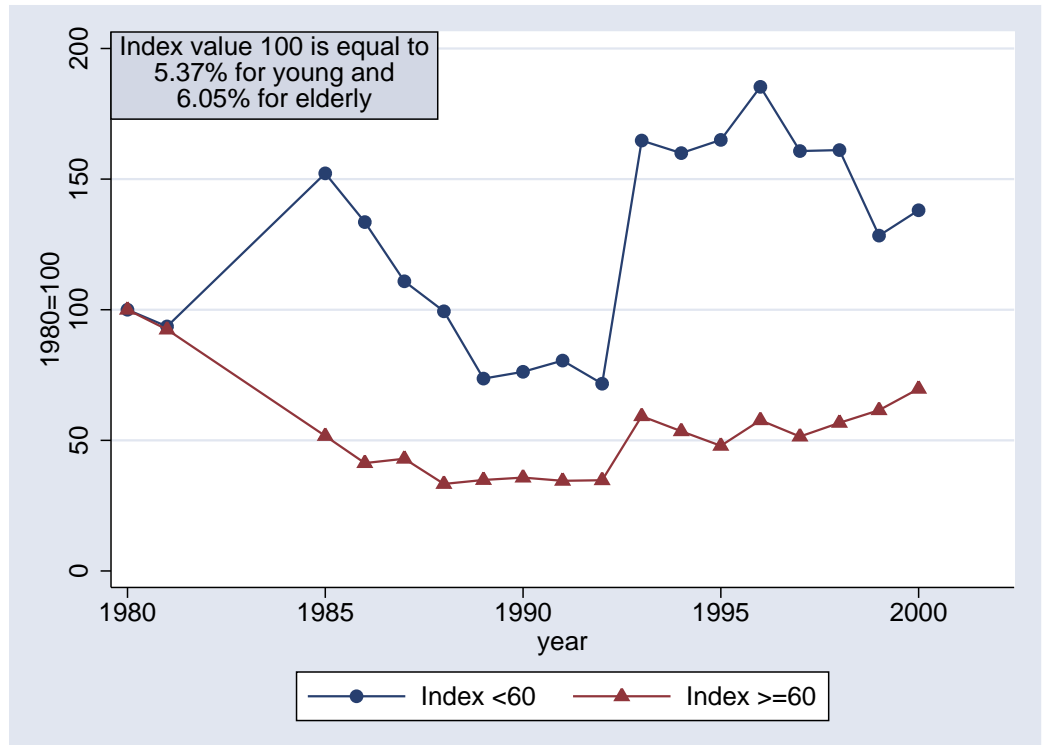


Figure 13: Trends of absolute poverty (40\% of median 1985 non-elderly income).

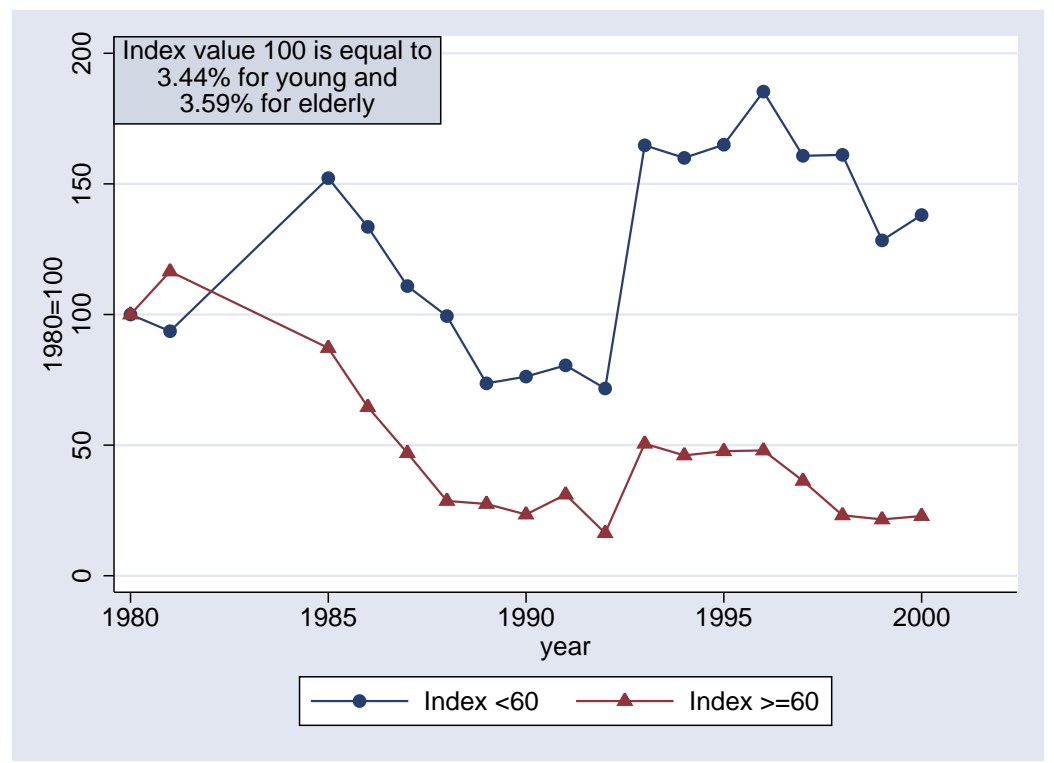

Figure 14: 10th, 50th, 90th percentiles of income.

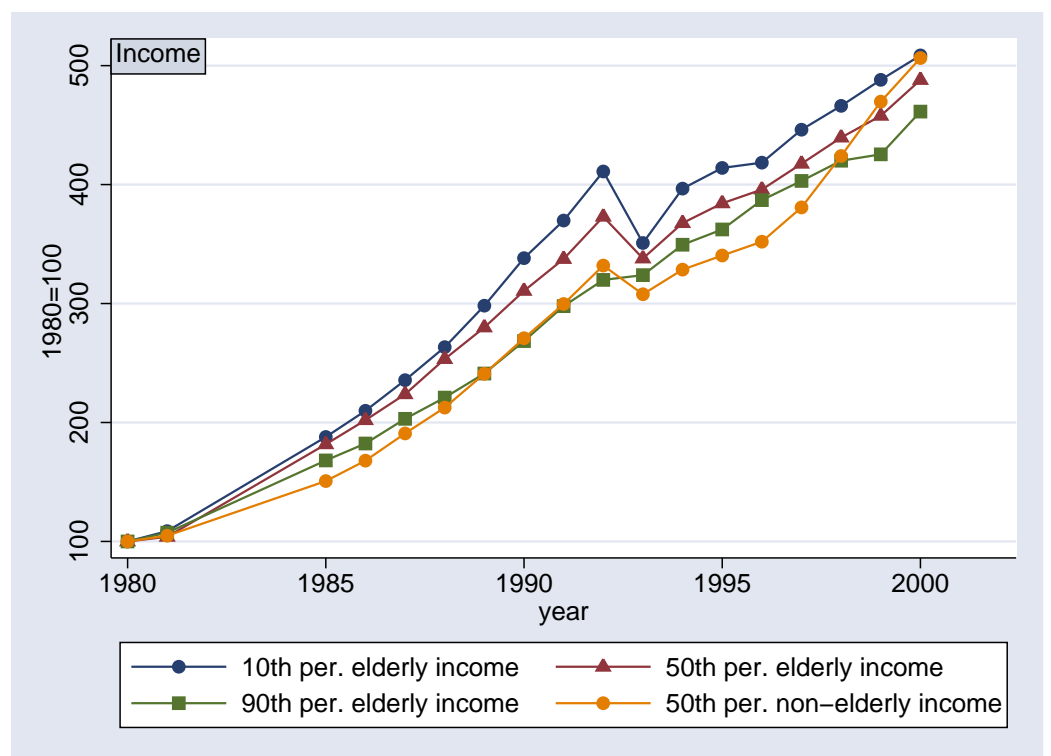


Figure 15: Trends of consumption.

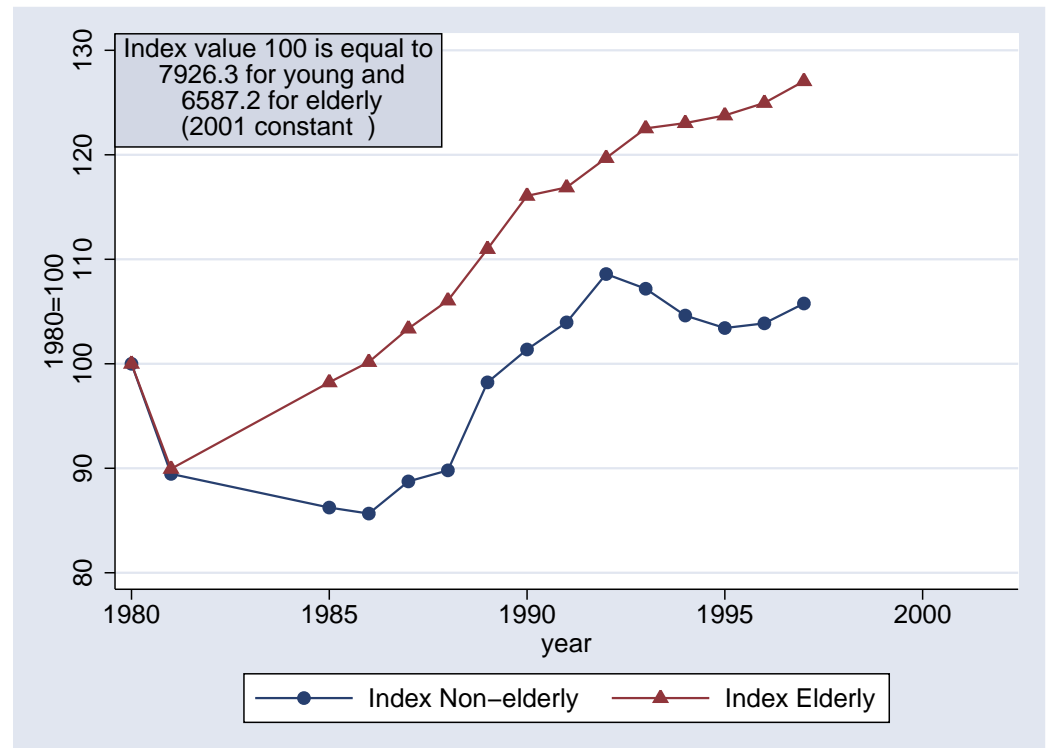

Figure 16: Trends of relative consumption poverty (40 percent of the non-elderly median consumption).

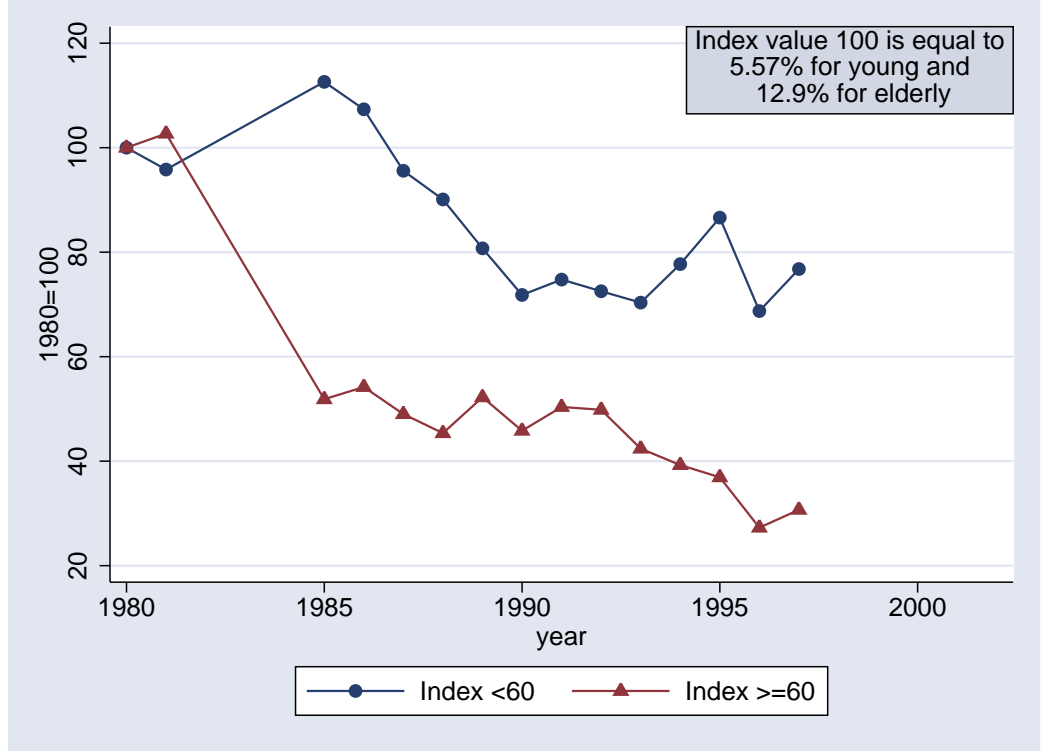


Figure 17: Trends of absolute consumption poverty (40 percent non-elderly 1985 median ).



Figure 18: 10th, 50th, 90th percentiles of consumption.

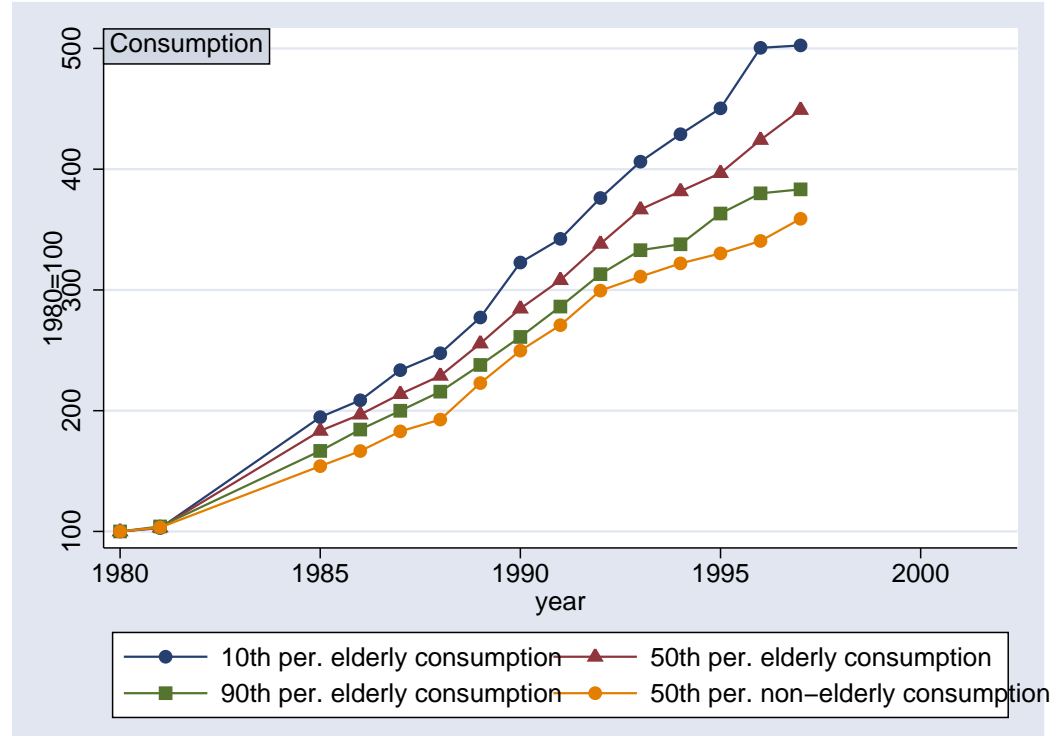


Figure 19: Trends of life satisfaction.

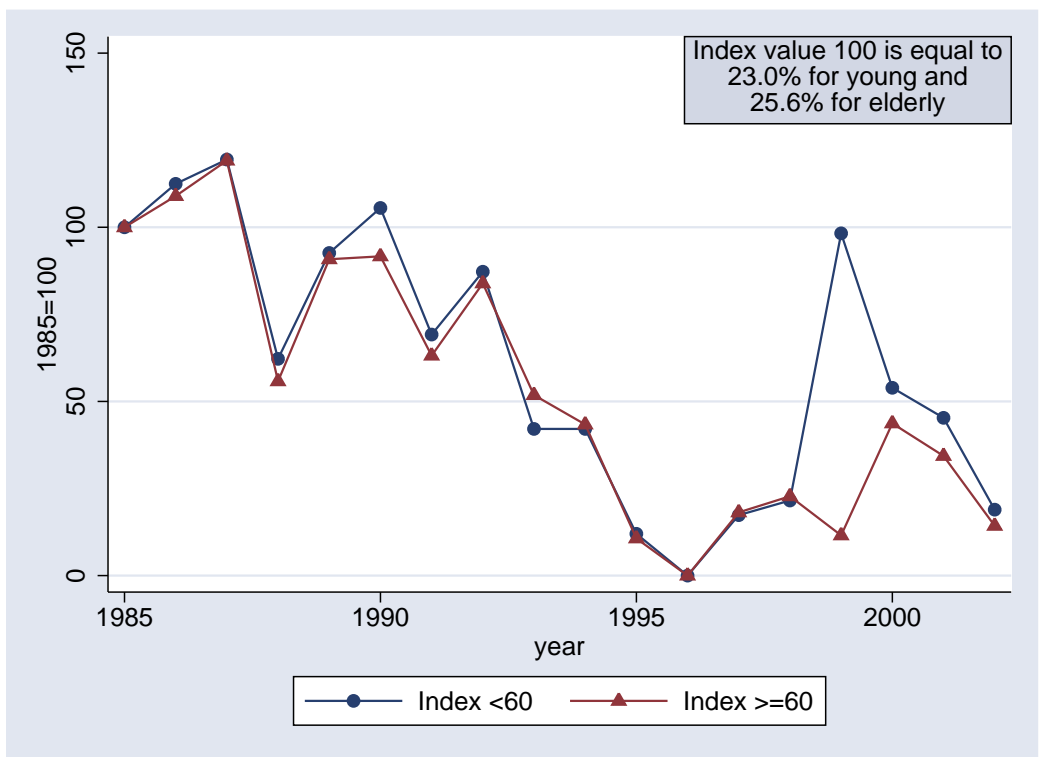

Figure 20: Trends of life dissatisfaction.

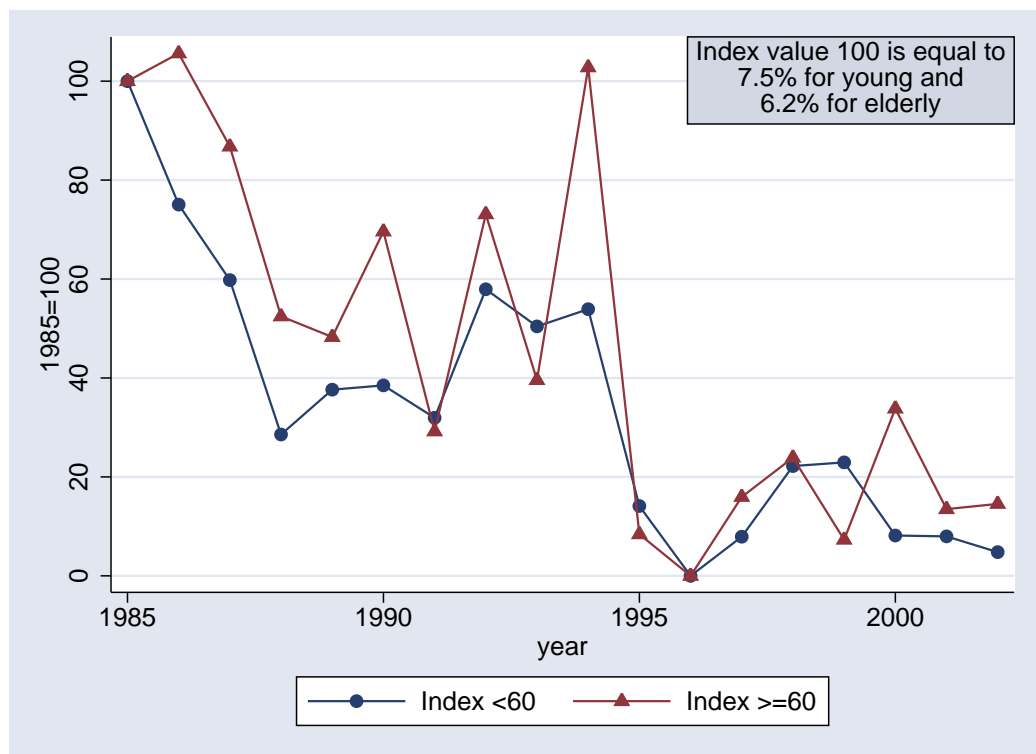


Figure 21: Trends of health status (I). Good Health.

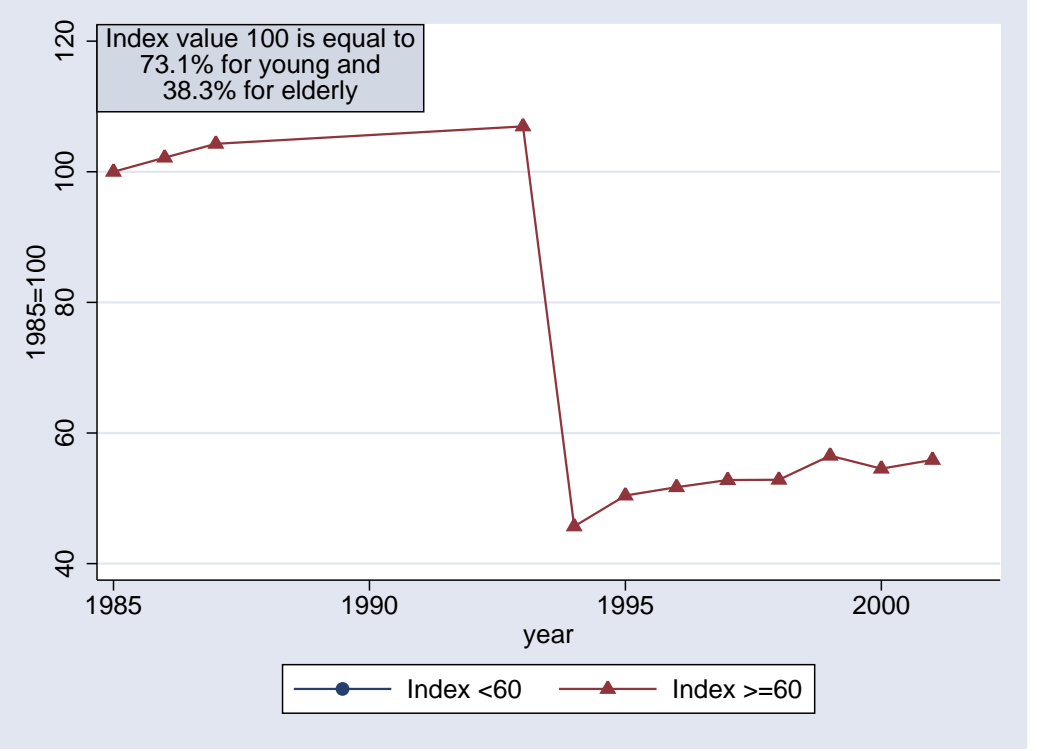

note: from 1985 to 1993: ES; 1994+ ECHP

Figure 22: Trends of health status (II). Bad Health.

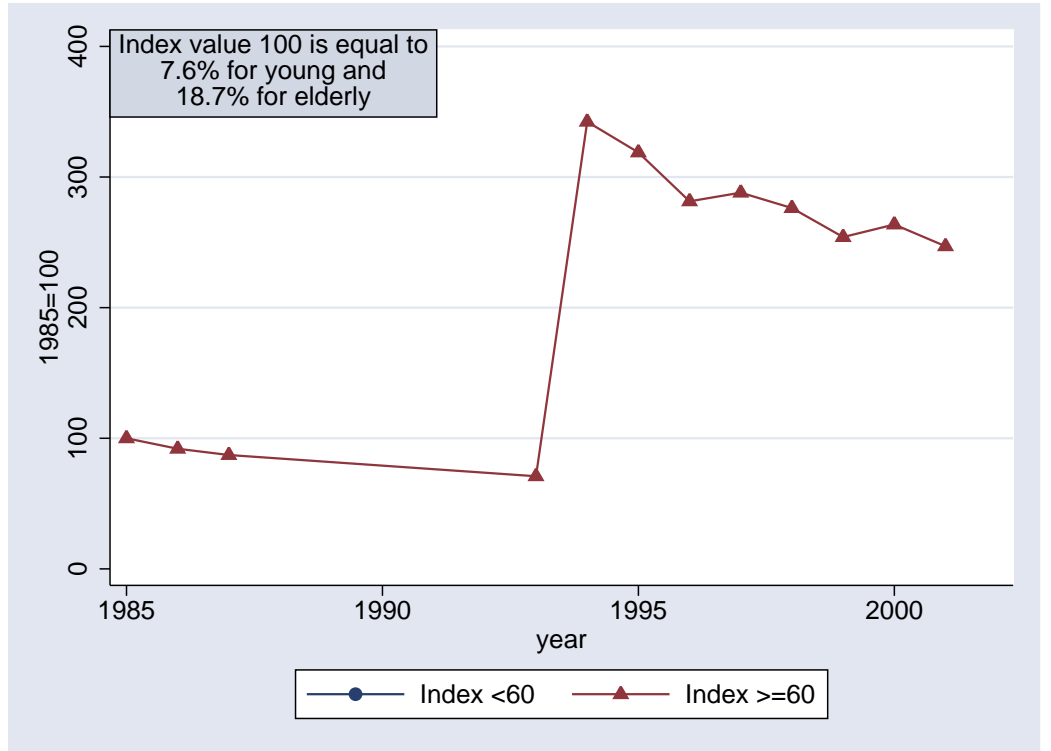

note: from 1985 to 1993: ES; 1994+ ECHP 
Table 7: Trends in life satisfaction and health.

\begin{tabular}{|c|c|c|c|c|c|c|c|c|}
\hline \multirow[b]{2}{*}{ Year } & \multirow[b]{2}{*}{ Group } & \multicolumn{2}{|c|}{ Satisfaction } & \multicolumn{3}{|c|}{ \% Fair+Bad Health } & \multicolumn{2}{|c|}{ Survival } \\
\hline & & Very & Not & All & Male & Female & $\begin{array}{r}\text { Life Exp. } \\
\text { at } 55\end{array}$ & $\begin{array}{r}\text { Share Surv. } \\
\text { at } 75\end{array}$ \\
\hline 1965 & - & - & - & - & - & - & 21.95 & 52.98 \\
\hline 1970 & - & - & - & - & - & - & 22.69 & 55.82 \\
\hline 1975 & - & - & - & - & - & - & 23.43 & 58.67 \\
\hline 1980 & - & - & - & - & - & - & 24.17 & 61.52 \\
\hline 1985 & all & 0.235 & 0.071 & 0.357 & 0.306 & 0.405 & - & 一 \\
\hline 1985 & $55+$ & 0.249 & 0.081 & 0.578 & 0.524 & 0.632 & 24.91 & 64.37 \\
\hline 1986 & all & 0.263 & 0.058 & 0.345 & 0.304 & 0.382 & - & - \\
\hline 1986 & $55+$ & 0.262 & 0.061 & 0.557 & 0.519 & 0.587 & 25.06 & 64.94 \\
\hline 1987 & all & 0.282 & 0.047 & 0.331 & 0.282 & 0.377 & - & - \\
\hline 1987 & $55+$ & 0.277 & 0.055 & 0.560 & 0.503 & 0.605 & 25.21 & 65.51 \\
\hline 1988 & all & 0.142 & 0.024 & - & - & - & - & - \\
\hline 1988 & $55+$ & 0.140 & 0.032 & - & - & - & 25.36 & 66.07 \\
\hline 1989 & all & 0.217 & 0.028 & - & - & - & & - \\
\hline 1989 & $55+$ & 0.225 & 0.034 & - & - & - & 25.50 & 66.64 \\
\hline 1990 & all & 0.240 & 0.032 & - & - & - & & - \\
\hline 1990 & $55+$ & 0.229 & 0.052 & - & - & - & 25.65 & 67.21 \\
\hline 1991 & all & 0.159 & 0.022 & - & - & - & & - \\
\hline 1991 & $55+$ & 0.155 & 0.017 & - & - & - & 25.80 & 67.78 \\
\hline 1992 & all & 0.203 & 0.043 & - & - & - & & - \\
\hline 1992 & $55+$ & 0.203 & 0.051 & - & - & - & 25.95 & 68.35 \\
\hline 1993 & all & 0.104 & 0.034 & 0.314 & 0.268 & 0.358 & - & - \\
\hline 1993 & $55+$ & 0.116 & 0.027 & 0.522 & 0.465 & 0.568 & 26.10 & 68.92 \\
\hline 1994 & all & 0.100 & 0.045 & 0.374 & 0.334 & 0.412 & - & - \\
\hline 1994 & $55+$ & 0.107 & 0.058 & 0.680 & 0.625 & 0.725 & 26.25 & 69.49 \\
\hline 1995 & all & 0.027 & 0.009 & 0.349 & 0.303 & 0.391 & - & - \\
\hline 1995 & $55+$ & 0.025 & 0.007 & 0.646 & 0.581 & 0.699 & 26.39 & 70.06 \\
\hline 1996 & all & - & - & 0.329 & 0.291 & 0.364 & - & - \\
\hline 1996 & $55+$ & - & - & 0.640 & 0.578 & 0.689 & 26.54 & 70.63 \\
\hline 1997 & all & 0.041 & 0.007 & 0.326 & 0.287 & 0.362 & - & - \\
\hline 1997 & $55+$ & 0.042 & 0.009 & 0.635 & 0.575 & 0.684 & 26.69 & 71.20 \\
\hline 1998 & all & 0.051 & 0.016 & 0.325 & 0.287 & 0.359 & - & - \\
\hline 1998 & $55+$ & 0.053 & 0.017 & 0.630 & 0.572 & 0.677 & 26.84 & 71.77 \\
\hline 1999 & all & 0.104 & 0.009 & 0.308 & 0.271 & 0.342 & - & - \\
\hline 1999 & $55+$ & 0.040 & 0.006 & 0.608 & 0.560 & 0.646 & 26.99 & 72.34 \\
\hline 2000 & all & 0.121 & 0.009 & 0.312 & 0.274 & 0.346 & 27.14 & 72.91 \\
\hline 2000 & $55+$ & 0.107 & 0.019 & 0.627 & 0.568 & 0.674 & 27.14 & 72.91 \\
\hline 2001 & all & 0.100 & 0.006 & 0.323 & 0.287 & 0.356 & 27.28 & 73.48 \\
\hline 2001 & $55+$ & 0.087 & 0.009 & 0.617 & 0.561 & 0.661 & 27.28 & 73.48 \\
\hline 2002 & all & 0.042 & 0.005 & - & - & - & 27.43 & 74.05 \\
\hline 2002 & $55+$ & 0.036 & 0.007 & - & - & - & 27.43 & 74.05 \\
\hline 2003 & $55+$ & - & - & - & - & - & 27.58 & 74.62 \\
\hline
\end{tabular}


to all age groups, as the time series for the elderly closely tracks that for the population at large. Notice that the subjective evaluation of health conditions also points to a bleak situation, as the percentage of those who consider themselves to be in either fair or bad health (as opposed to good or excellent) increases monotonically and dramatically for the whole sample period. Objective measures of health, though, seem to provide a completely different picture of the situation. Life expectancy at 55 has increased from 22 to almost 28 years over the 1965-2003 period and the (absolute) rate of improvement does not seem to have declined during the last decade: each ten years of calendar time, 55+ years old Spaniards add 1.5 years to their life expectancy. Similarly, the chances at birth of surviving until age 75 have dramatically increased from about even to the current three quarters.

On a more methodological line, the dramatic discrepancy between objective and subjective measures of health and living conditions should issue an important warning on the reliability of polls or other "subjective" measures of economic and physical conditions. Quite clearly, as these examples show, people seem to systematically report "feelings" either in a confused or a strategic form. Even more startling is the fact that, when self evaluating health conditions, women seem to be, at all ages, lot more pessimist than men: in our sample the percentage of those reporting poor health conditions is systematically 8 to 10 points higher among women than among men. Notoriously, women's life expectancy is, in Spain as everywhere else, substantially higher than men's. In other words: beware of socio-psychological opinion polls, stick to the old revealed preferences tradition that has served economists so well till now.

\section{Simulated Benefits}

Spanish elderly seem to be doing better and better, their income has increased both in absolute and relative terms, so have their consumption, health and life expectancy, while poverty seems to be dramatically and steadily decreasing, and inequality remains stable at relatively low levels. We ask then: what did bring about all this wellbeing? In particular, which legislative and regulatory changes in the social security legislation, if any, account the most for the improvement in the living conditions of Spanish elderly? As the data reported so far suggest, the average elderly Spaniard is working a lot less than in the past, consuming a lot more, and living a longer and better life. This may have certainly come from a sudden increase in the return to their accumulated life-time savings but the data, see above Figure 3, have already told us that this cannot be the case. In fact, the data show that the dramatic improvement in the per capita income of the elderly is basically due to one and one source only: the social security benefits. Hence, it is worth asking: which legislative changes made benefits per capita increase so much?

We will try to answer this by creating various series of simulated benefits, obtained by trying to "turn off" some of the determinants of actual benefits so as to concentrate on the impact of legislative changes versus changes in the level of wages or in employment patterns. With this methodology we hope to capture legislative variations in the system over time, and to separate them from changes in the labor force and its characteristics. Ideally, what we would like to measure is the impact that legislative and regulatory changes (i.e. changes in the formal rules) per-se have had on per capita benefits at every age from 60 years onward, for both males and females. It is not clear, though, that this can be fully achieved in any meaningful way by means of the data available to us.

Consider the following fact: the benefits accruing to an individual with characteristics $\omega$ during calendar year $t$ are determined by two factors: the laws in place in year $t$ and the characteristics $\omega$ 
of the recipient, which include among other, age, sex and number of contributive years. The idea of the simulated benefit approach, is to abstract from all differences in characteristics of recipients and focus solely on variation in benefits that arise from law changes. But, as individuals have different characteristics both before and after legislative changes are implemented, a given set of law changes will have very different effects on individual with different characteristics. Ideally, again, the simulated benefits approach would take exactly the same person (but notice: which kind of person?) and put him/her in every single birth cohort, and then compute his/her benefits in every single calendar year since this person turns 60 , which would obviously vary with the birth cohort. In this way, it is claimed, we would hold constant the personal characteristics, and any benefits variation that we saw over time or across birth cohorts would have to be due to law changes. But, again, this is not completely true, and for two reasons. First, as we have already said, because there are very many different sets of individuals with different personal characteristics at any past date of birth or at any year in calendar time, and a given law change may increase benefits for type $\omega_{1}$ between ages $a$ and $a^{\prime}$ while it decreases benefits for type $\omega_{2}$ during the same age interval. Second, because any law change induces different behavioral responses from individuals with different characteristics, and benefits do depend also on behavioral responses as the latter determine things such as, for example, the number of contributive years at the time of retirement.

\subsection{Construction of simulated benefits}

We construct various simulated benefit measures. The first two are common to all chapters in this volume. They are

- (SB1) Partially simulated benefits, and

- (SB2) Fully simulated benefits.

In order to construct the Partially simulated benefits measure we proceed as follows:

1. We use either the 50 percentile of the Spanish wage distribution [OPTION B1A] constructed from the 1995 Encuesta de Estructura Salarial (EES, the 5, 10, 25, 50 ,75, 90, 95 percentiles of the distribution are shown in figure 23), or the 25, 50 and 75 percentiles constructed from covered wages by sex, age and year [OPTION B1B(25,50,75)] (Sources: new HLSS 1990 and 2004 files.)

2. We correct the 50 percentile wage profile with inflation and use it to construct simulated benefits (SB) for each possible retirement age and calendar year since the beginning of the sample period.

3. For each age $a$, we construct a simulated benefits (SB) measure as a weighted average of benefits at any previous feasible retirement age $(a)$ in each year $(t)$, where the weights are the retirement probabilities at each age $a$ in each year $t$ :

$$
S B_{a}^{t}=\sum_{j=\min }^{a} \quad \text { age } B^{t} \operatorname{Pr}^{t} \text { (Ret.) }
$$

In order to construct the Fully simulated benefits, steps 1 and 2 are as above. Steps 3 and 4 only differ slightly since we use fixed retirement probabilities and participation levels. In both cases we use either the 1995 wage distribution (OPTION SB2A) or the average covered wages by quantile (OPTION SB2B $(25,50,75$, see figure 26)).

In the analysis of the next section, apart from the set of simulated benefits measures just defined, we also compute: 
Figure 23: Wage profiles by quantile $(5,10,25,50,75,90,95)$. In log of 1995 Spanish pta.

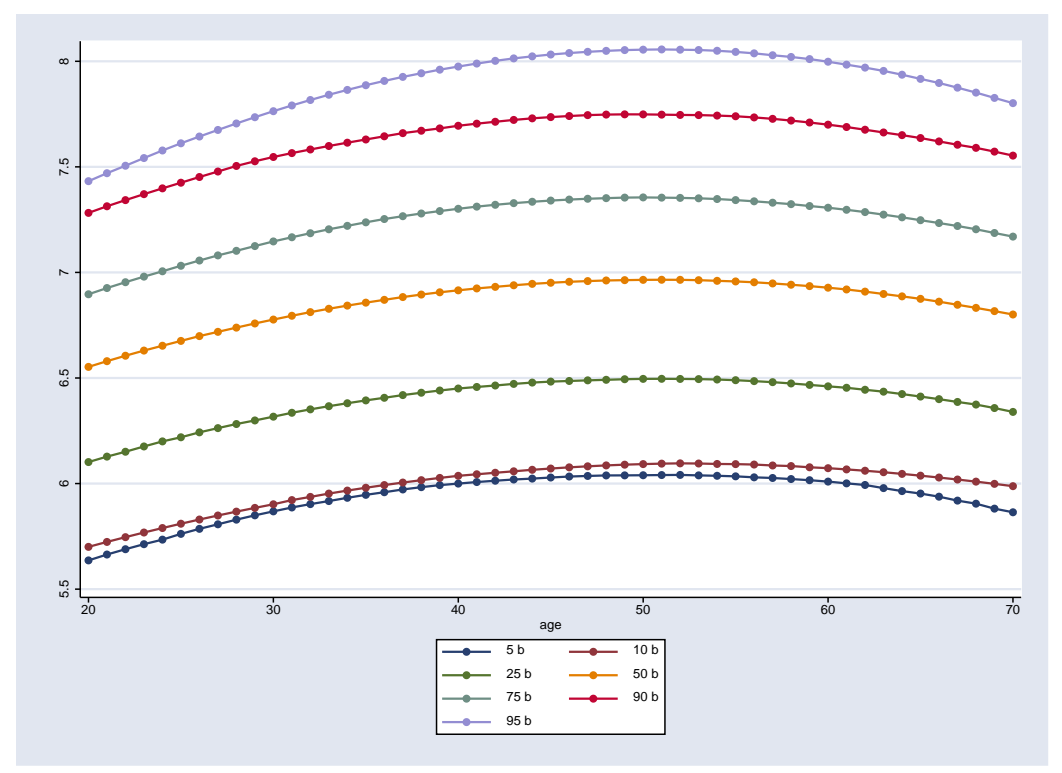

- (SB3) Minimum benefits entitlement, which may depend on age and marital status.

The minimum benefit variable at age $a, S B 3_{a}$, is constructed as:

$$
S B 3_{a}=f m_{a} * S B 3_{a}(m)+\left(1-f m_{a}\right) * S B 3_{a}(n m)
$$

where $\mathrm{fm}_{a}$ stands for the fraction of married at age $a ; m$ stands for married and $\mathrm{nm}$ for nonmarried. Note that the minimum benefit varies with age (60-64 and 65+) and marital status (married vs unmarried).

- (SSB) Finally, we construct various indicators of actual Social Security benefits:

1. Mean of actual SS benefits by cell.

2. $10^{\text {th }}, 50^{\text {th }}$ and $90^{\text {th }}$ percentile of actual benefits in order to use them for in respectively the $10^{t h}, 50^{t h}$ and $90^{t h}$ percentiles of income and consumption.

3. Actual benefits average for those below either the relative or the absolute income poverty line (40 percent of the non-elderly median income in the current year -relative-, or in year 1985 -absolute).

\subsection{Description of Variation}

Figures 24 and 25 describe, for men and women respectively, the variation of our measures of simulated benefits by year (first row), cohort (second row) and age (third row). The first row compares partial and fully simulated benefits for options A and B (based, respectively, on the profiles of actual wages and covered wages). The second row compares, for the same cases, the same measures computed for various cohorts. Finally, the third row of graphs allows for comparisons by age at which benefits are received. Note first that there is no real difference between sexes, all 
variations are remarkably similar. The overall historical pattern is the same we already noticed before when considering actual benefits. The estimated benefits according to age suggest a strong increase in benefits received as people become older, signaling a bias of the system in favor of the very old. This, in our view, is probably due to the effect of early retirement and the penalization it entails. Almost all the retirees in the age groups 60-65 are early retirees, who receive pension benefits up to $40 \%$ smaller than those accruing to people retiring at the age of 65 or older. The cohort effect, line two, is also visible, with earlier cohorts treated overall better than the most recent ones; this confirms the slow down in the growth rate of benefits during the most recent years.

\section{Estimating the Causal Relationship Between Programs and Well Being}

We carry out the analysis at two levels of data disaggregation: (L1) age-year-gender cells; and, (L2) age-year-gender-education cells. For the fist level of analysis, all the benefit measures are employed. However, for the second level, we restrict to B1B (Partial simulated benefits) and B2B (Fully simulated benefits). Educational groups are defined as: (Group 0) less than high school, and (Group 1) high school and above. We assign the 25th percentile of the covered wages profile to group 0 (less than high school) and the 75th percentile of the covered wages profile to educational group 1. [See figure 26 for an illustration]. Finally, inspection of the data reported in figure 27 recommends carrying out the analysis for all individuals aged $60+$.

\subsection{Regressions for age-year-gender cells}

Our main purpose is to identify the impact of Social Security benefits $(S S B)$ on wellbeing measures $(W B)$. Identification of the effect of SS benefit variables proceeds in three steps.

1. We estimate first stage regressions of actual Social Security benefit variables (mean, 10th, 50th, 90th, and poverty SS income), the corresponding simulated benefit concept (mean, 10th, 50th, and 90th), and other controls.

$$
S S B_{a t f}=\delta S B_{a t f}+X_{a t f}^{\prime} \alpha+\beta_{a} \cdot a+\beta_{y} \cdot t+\beta_{f} F+Z_{c}^{\prime} \gamma+u_{a t f}
$$

where $S S B$ denotes the corresponding actual Social Security benefit concept, $S B$ the simulated benefit concept, and $u$ denotes an error term. The regression also controls for age $(a)$, calendar year $(t)$, gender ( $F=1$, for female), and two sets of control variables:

- $Z_{c}$ : Predetermined (as of retirement) characteristics of the birth cohort,

- $X_{t}$ : Mean outcomes of the non-elderly in that year, to capture time series effects (e.g. in income equations, include average income of non-elderly)

2. In the second stage, for each measure of well-being $(W B)$, we estimate reduced form models. More precisely, we regress wellbeing $(W B)$ variables against simulated benefits variables $(B)$ and the set of controls listed above:

$$
W B_{a t f}=\delta S B_{a t f}+X_{a t f}^{\prime} \alpha+\beta_{a} \cdot a+\beta_{y} \cdot t+\beta_{f} F+Z_{c}^{\prime} \gamma+v_{a t f}
$$

where $B_{t}$ denotes the benefit measure and $v$ is an error term. 
Figure 24: Simulated benefits by year, by cohort and by age group. Male (in 2002 euros).

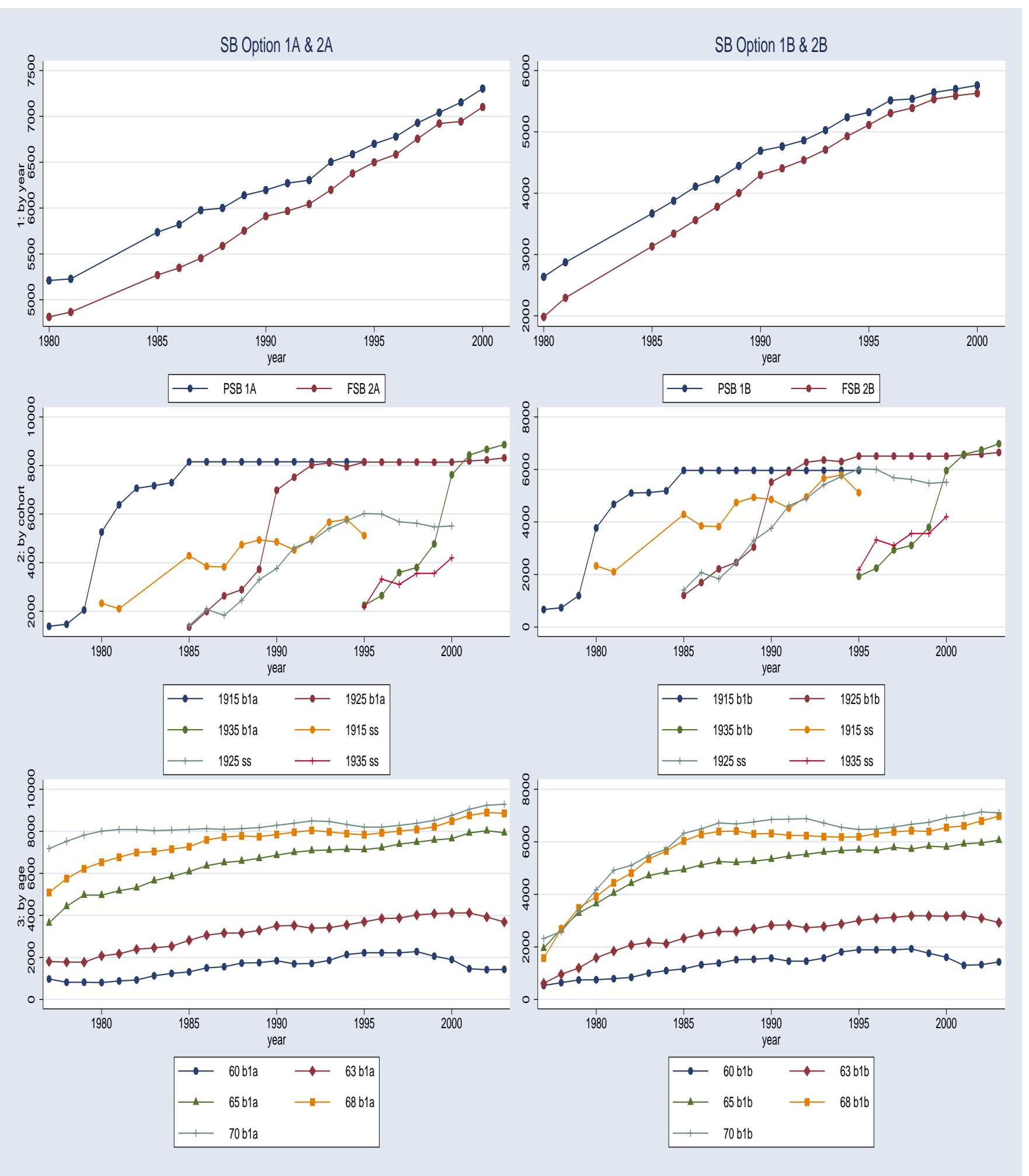


Figure 25: Simulated benefits by year, by cohort and by age group. Female (in 2002 euros).

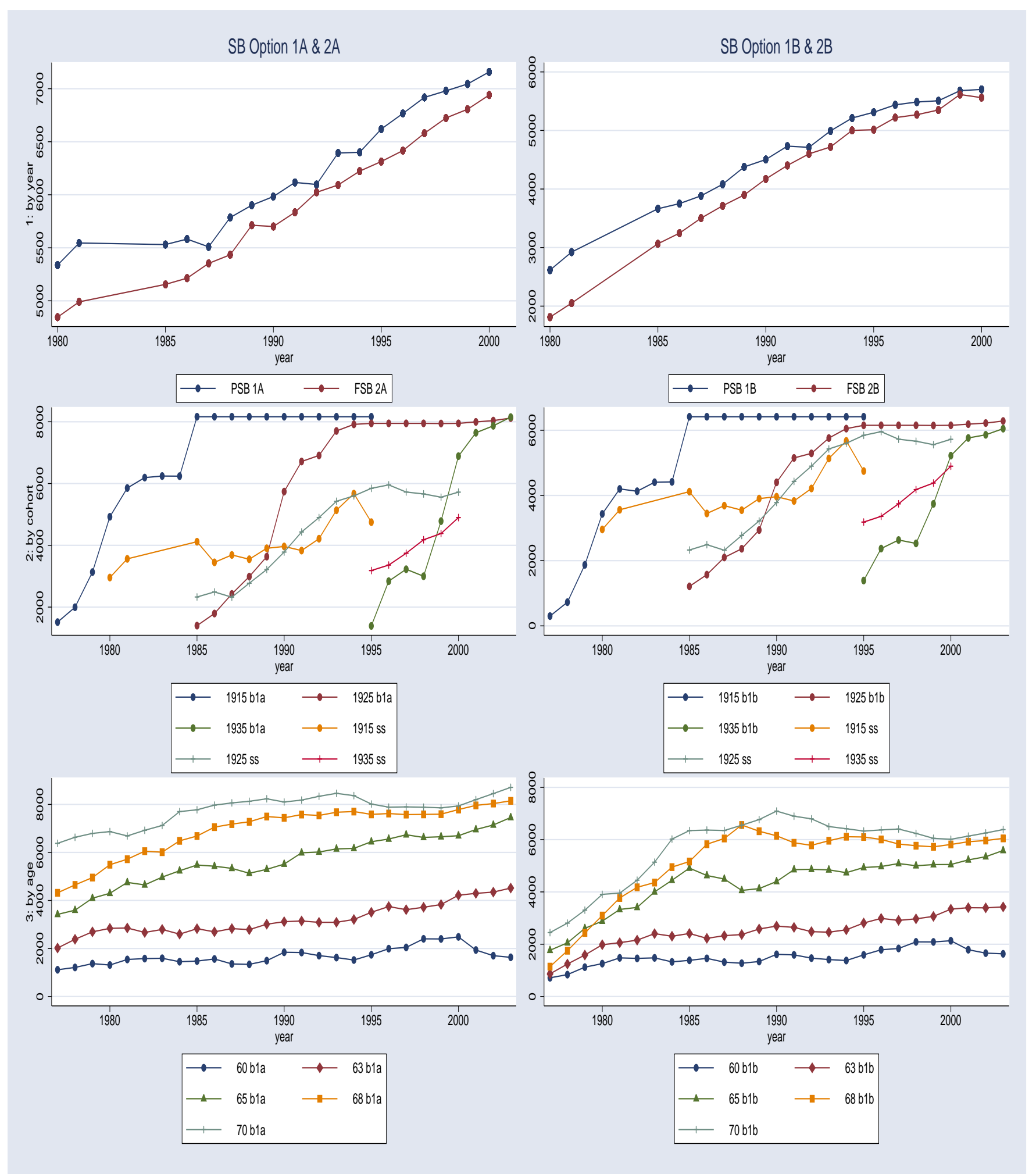


Figure 26: Simulated benefits by year, gender and quantile. (in 2002 euros).

Figure 27: Benefits vs income by gender

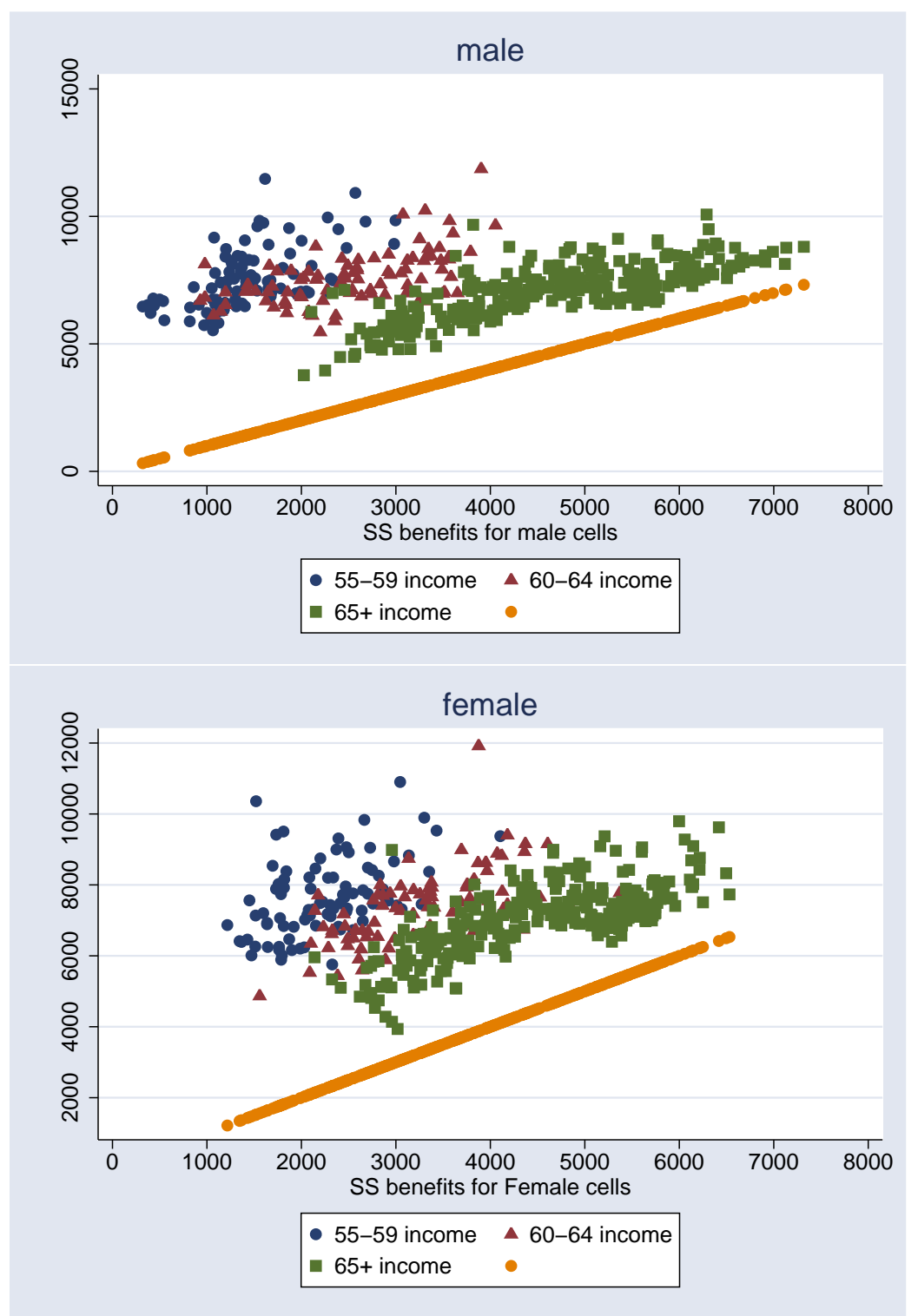


3. In the third stage we estimate the relationship between wellbeing $(W B)$ variables and actual Social Security benefits $(S S B)$ :

$$
W B_{a t f}=\delta S S B_{a t f}+X_{a t f}^{\prime} \alpha+\beta_{a} \cdot a+\beta_{y} \cdot t+\beta_{f} F+Z_{c}^{\prime} \gamma+v_{a t f}
$$

However, in this case the estimation is carried out by instrumental variables (IV) using simulated benefit variables $(S B)$ as instruments for actual Social Security benefit variables.

The following table describes the mapping between wellbeing indicators, actual SS benefits and simulated benefits.

\begin{tabular}{lll}
\hline \hline Well-Being indicator & actual SS benefit concept & simulated benefit concept \\
\hline $\begin{array}{l}\text { Income, Consumption } \\
\text { Satisfied, unsatisfied } \\
\text { Good and Bad Health }\end{array}$ & average SS income & median simulated benefits \\
\hline $\begin{array}{l}\text { Relative and absolute } \\
\text { income and cons poverty }\end{array}$ & $\begin{array}{l}\text { Average SS income } \\
\text { for those below } \\
\text { poverty per income and cons. }\end{array}$ & 10th percentile sim. ben. \\
\hline 50th per income and cons. & 50th percentile SS income & median simulated benefits \\
\hline 90th per income and cons. & 90th percentile SS income & 90th per. simulated benefits \\
\hline
\end{tabular}

All three steps are carried out using simulated benefits concepts $\operatorname{SBj} A, \operatorname{SBj} B, j=1,2$ ). All regressions are weighted by the cell size in the micro-data.

\subsection{Regressions for age-year-gender-education cells}

In a second round of regressions we collect individuals according to their educational status and follow the same three steps described above (1st stage regressions, reduced form and instrumental variables). However, in this case, since there is more variation in the data, we consider a richer set of controls and include education, age and year dummies interacted with gender.

1. The first stage regressions is given by:

$$
S S B_{a t f e}=\delta S B_{a t f e}+\nu_{a}+\beta_{e} E+d_{t}+\beta_{f} F+\left\{F * d_{t}\right\}+\{F * E\}+\{a * F\}+v_{\text {eatf }}
$$

2. The reduced form regression is given by:

$$
W B_{a t f e}=\delta S B_{a t f e}+\nu_{a}+\beta_{e} E+d_{t}+\beta_{f} F+\left\{F * d_{t}\right\}+\{F * E\}+\{a * F\}+v_{\text {eatf }}
$$

3. The $\mathbf{I V}$ regression is given by:

$$
W B_{a t f e}=\delta S S B_{a t f e}+\nu_{a}+\beta_{e} E+d_{t}+\beta_{f} F+\left\{F * d_{t}\right\}+\{F * E\}+\{a * F\}+v_{\text {eatf }}
$$

In this case the actual benefit variable is instrumented by using partial simulated benefits (SB1B), or fully simulated benefits (SB2B). In simulating benefits for the highly educated group we use in either SB1B or SB2B the 75th percentile of the covered wages profile, while for the less educated group we use the 25 th percentile of covered wages.

Again, all regressions are weighted by the cell size in the micro-data. 


\subsection{Results for age-year-gender cell regressions}

Table 8 reports the linear age and year regression results (first stage, reduced form and IV) for the benefit coefficient $\delta$ when using benefit concepts SB1A (PS columns) and SB2A (FS columns). simulated benefits (SB1A and B2A). In all cases the results vary very little by simulation concept, either partially simulated or fully simulated benefits, so we comment them jointly.

The estimated coefficient of the benefit variables has, in many cases, the correct sign but is not, as a rule, very significant. For example, the reduced and IV coefficients for the average income case show the wrong sign but aren't significant. In case of consumption the corresponding coefficient while showing the correct sign are insignificant. Also relevant is the evidence we obtain by quantile. The IV coefficient for the 10th quantile regressions of either income and consumption is small but significant. They imply that a euro of Social Security benefits translates into approximately 10 cents of euro of income and consumption respectively. The effect for the 50th quantile is very different since it is insignificant for income and very significant for consumption. In the latter case an euro of SS benefits increases 20 cents of euro the level of consumption. Finally the effect for the 90th percentile has the correct sign but is insignificant.

The effect of SS benefit on poverty is much clearer. An increase of 1000 euros in SS income, decrease relative and absolute income poverty by one third. The effect in consumption poverty is smaller but still important, since it reduces it around 25 percent. The effect of either satisfaction or health variables has the correct sign and is significant except for the unsatisfied variable.

Table 9 reports the results from simular regression but using simulated benefit concepts B1B (PS columns) and B2B (FS columns). Under the alternative simulated benefit concept the qualitative picture remains the same. However, the significance of the coefficients is greater because the simulated data has, in this case greater variation. The consequences are evident: now the effect of SS benefits in the fraction of unsatisfied and the fraction with bad health is significant.

\subsection{Results with educational groups}

Here we do exactly the same, allowing to control for the educational group of the individual. Table 10 reports the regression results when using SB1B (columns labelled PS), SB2B (columns labelled FS) concepts.

As one would have expected, the fit of the model is, as a rule, substantially better than in the case where educational groups are not considered; this is particularly true for income and consumption regressions. For instance, an euro of SS benefits translates into 0.80 euros of average income. The effect is also very substantial for the 10th and 90th percentile of income (0.6 and 1.82 when PS benefits is used as instrument for actual SS benefits, respectively). Results for average or median consumption are much more modest (around 0.20). Finally, the effect for the 90th percentile of consumption are very important since an euro of SS benefits translates into between 0.75 (PS) and 1 (FS) euro of consumption.

Poverty results are even stronger than they were in the previous tables. In this case, 1000 extra euros of SS income practically eliminate income poverty and reduces by more than a third (depending on the specification) consumption poverty. After adding more variation to the analysis the effect of benefits in satisfaction turns now significant. The coefficients on unsatisfied and health variables remain little or no significant. 
Figure 28: The relevance of non-contributive pensions since 1991.



\subsection{Results when considering minimum benefits as a benefit measure}

In the Spanish case, legislated minimum benefits constitute a powerful tool for redistributing income toward a certain subset of the elderly people. In this subsection we briefly evaluate their explanatory power with respect to well-being measures.

In Table 11 we present the result of fitting well-being indicators as a function of the minimum pension (benefit measure SB3) and of the average annual non-contributive pension per individual aged $65+$, these being the two key policy tools used for redistributing income toward the elderly poor in Spain. The presence of a non-negligible non-contributive pension, introduced in 1991, helps explaining the change in income and consumption levels of the poorest elderly that have occurred during the 1990s. Figure 28 illustrates the relevance of this program since its inception; it reports the fraction of $65+$ having a non-contributive pension, and the average annual benefit received by each individual aged $65+$.

As in the previous tables, most of the coefficients are significant, especially when considering age and year dummies. The minimum pension works particularly well in explaining the 10th percentile of income, consumption, and poverty measures. Again, also in this case the explanatory variable does a poor job in explaining satisfaction indices and, to a lesser extent, health variables. The inclusion of the average annual non-contributive benefit per older individual improves the fit of all models.

\section{Conclusions}

The Spanish pension system has apparently not suffered big changes in the period 1975-2000. Only the changes in the pension formula are of some relevance. In fact, the most important changes in the system have been the increase in the generosity of the minimum pension and survival pension, and the introduction of non-contributive pension. Minimum pension supplements and non-contributive pension (mostly for women) represent well above 10 percent of pension expenditure, which helps understand the continuous improvement of the Spanish elderly. However, still we are able to find 
Table 8: Well-being indicators vs benefits regressions. Age-gender-year cells. Simulated benefit concepts: SB1A (PS) and SB2A (FS). Spain: ages 60-80+ (I). Linear age and year specification with cohort controls.

\begin{tabular}{|c|c|c|c|c|c|c|c|c|}
\hline \multirow[b]{2}{*}{ age $60^{*}$} & \multirow{2}{*}{$\begin{array}{r}\text { Mean of } \\
\text { dep. }\end{array}$} & \multirow{2}{*}{$\begin{array}{r}\# \\
\text { obs }\end{array}$} & \multicolumn{2}{|c|}{ First Stage } & \multicolumn{2}{|c|}{ Reduced Form } & \multicolumn{2}{|c|}{ IV } \\
\hline & & & $\mathrm{PS}$ & FS & PS & $\mathrm{FS}$ & PS & FS \\
\hline Mean SS income & 4196.0 & 756 & 0.2835 & 0.3519 & - & - & - & - \\
\hline s.e. & & & 0.0084 & 0.0093 & - & - & - & - \\
\hline Rel Pov SS inc & 1322.2 & 655 & 0.1387 & 0.1451 & - & - & - & - \\
\hline s.e. & & & 0.0178 & 0.0194 & - & — & - & — \\
\hline Abs Pov SS inc & 754.5 & 499 & 0.1247 & 0.1099 & - & - & - & 一 \\
\hline s.e. & & & 0.0203 & 0.0231 & - & - & - & - \\
\hline $10^{\text {th }}$ Pct SS income & 1315.0 & 756 & 0.3818 & 0.4527 & - & - & - & - \\
\hline s.e. & & & 0.0200 & 0.0226 & - & - & - & — \\
\hline $50^{t h}$ Pct SS income & 3751.0 & 756 & 0.2930 & 0.3565 & - & - & - & - \\
\hline s.e. & & & 0.0088 & 0.0103 & - & - & - & - \\
\hline $90^{t h}$ Pct SS income & 7423.9 & 756 & 0.2042 & 0.2361 & - & - & - & - \\
\hline s.e. & & & 0.0106 & 0.0123 & - & - & - & - \\
\hline Income & 7163.3 & 756 & - & - & -0.0092 & 0.0060 & -0.0324 & 0.0172 \\
\hline s.e. & & & - & 一 & 0.0104 & 0.0116 & 0.0371 & 0.0331 \\
\hline Rel. Inc. poverty ${ }^{a}$ & 3134.2 & 756 & 一 & 一 & -0.4807 & -0.6029 & -1.2591 & -1.3315 \\
\hline s.e. & & & - & - & 0.0709 & 0.0740 & 0.1826 & 0.1597 \\
\hline Abs. Inc. poverty ${ }^{a}$ & 1657.6 & 756 & - & - & -0.3559 & -0.3908 & -0.9324 & -0.8635 \\
\hline s.e. & & & - & - & 0.0495 & 0.0499 & 0.1252 & 0.1090 \\
\hline $10^{\text {th }}$ income & 3419.1 & 756 & - & - & 0.0769 & 0.1135 & 0.2015 & 0.2506 \\
\hline s.e. & & & 一 & - & 0.0123 & 0.0116 & 0.0315 & 0.0269 \\
\hline $50^{\text {th }}$ income & 6167.7 & 756 & - & - & -0.0024 & 0.0044 & -0.0081 & 0.0123 \\
\hline s.e. & & & - & - & 0.0105 & 0.0111 & 0.0359 & 0.0313 \\
\hline $90^{\text {th }}$ income & 11819 & 756 & - & 一 & -0.0266 & -0.0128 & -0.1313 & -0.0547 \\
\hline s.e. & & & - & 一 & 0.0162 & 0.0180 & 0.0821 & 0.0777 \\
\hline Consumption & 7345.3 & 630 & 一 & - & 0.0056 & 0.0218 & 0.0194 & 0.0618 \\
\hline s.e. & & & 一 & 一 & 0.0110 & 0.0135 & 0.0380 & 0.0384 \\
\hline Rel. cons.poverty ${ }^{a}$ & 6966.5 & 630 & - & - & -0.1845 & -0.3990 & -0.4795 & -0.9097 \\
\hline s.e. & & & - & - & 0.1050 & 0.1100 & 0.2753 & 0.2606 \\
\hline Abs. cons.poverty ${ }^{a}$ & 4786.9 & 630 & — & — & -0.1119 & -0.3204 & -0.2915 & -0.7328 \\
\hline s.e. & & & 一 & - & 0.0797 & 0.0783 & 0.2075 & 0.1868 \\
\hline $10^{\text {th }}$ consumption & 3065.5 & 756 & - & - & 0.0254 & 0.0388 & 0.0662 & 0.0888 \\
\hline s.e. & & & - & - & 0.0110 & 0.0120 & 0.0289 & 0.0280 \\
\hline $50^{t h}$ consumption & 6101.1 & 756 & — & — & 0.0075 & 0.0204 & 0.0252 & 0.0569 \\
\hline s.e. & & & - & - & 0.0085 & 0.0104 & 0.0286 & 0.0293 \\
\hline $90^{\text {th }}$ consumption & 12711 & 756 & 一 & - & 0.0036 & 0.0213 & 0.0170 & 0.0861 \\
\hline s.e. & & & 一 & 一 & 0.0183 & 0.0204 & 0.0859 & 0.0822 \\
\hline Satisfied $^{a}$ & 15596 & 756 & - & - & 0.7981 & 0.7324 & 2.5379 & 2.0152 \\
\hline s.e. & & & - & - & 0.2284 & 0.2363 & 0.6808 & 0.6292 \\
\hline Unsatisfied $^{a}$ & 2620.5 & 756 & - & - & -0.0551 & -0.0328 & -0.0799 & -0.0135 \\
\hline s.e. & & & 一 & 一 & 0.0694 & 0.0733 & 0.2443 & 0.2307 \\
\hline God health $^{a}$ & 36566 & 504 & - & - & -0.3535 & -0.3549 & -0.9726 & -0.9060 \\
\hline s.e. & & & - & - & 0.2167 & 0.2359 & 0.5959 & 0.5994 \\
\hline Bad health $^{a}$ & 24618 & 504 & 一 & - & -0.3855 & -0.4139 & -1.0620 & -1.0584 \\
\hline s.e. & & & - & - & 0.1722 & 0.1881 & 0.4747 & 0.4799 \\
\hline Cohort & Statt & . & ed & $n$ & ibution & & & \\
\hline
\end{tabular}


Table 9: Well-being indicators vs benefits regressions. Age-gender-year cells. Simulated benefit concept: SB1B (PS) and SB2B (FS). Spain: ages 60-80+ (I). Linear age and year specification with cohort controls.

\begin{tabular}{|c|c|c|c|c|c|c|c|c|}
\hline \multirow[b]{2}{*}{ age $60^{*}$} & \multirow{2}{*}{$\begin{array}{r}\text { Mean of } \\
\text { dep. }\end{array}$} & \multirow{2}{*}{$\begin{array}{r}\# \\
\text { obs }\end{array}$} & \multicolumn{2}{|c|}{ First Stage } & \multicolumn{2}{|c|}{ Reduced Form } & \multicolumn{2}{|c|}{ IV } \\
\hline & & & $\mathrm{PS}$ & FS & PS & FS & PS & FS \\
\hline Mean SS income & 4196.0 & 756 & 0.4268 & 0.3740 & - & - & - & - \\
\hline s.e. & & & 0.0149 & 0.0144 & - & - & - & - \\
\hline Rel Pov SS inc & 1322.2 & 655 & 0.1162 & 0.0994 & - & - & - & - \\
\hline s.e. & & & 0.0161 & 0.0151 & - & - & - & — \\
\hline Abs Pov SS inc & 754.5 & 499 & 0.0992 & 0.0732 & - & - & - & 一 \\
\hline s.e. & & & 0.0188 & 0.0174 & - & - & - & - \\
\hline $10^{\text {th }}$ Pct SS income & 1315.0 & 756 & 0.3832 & 0.3495 & - & - & - & - \\
\hline s.e. & & & 0.0173 & 0.0166 & - & - & - & — \\
\hline $50^{\text {th }}$ Pct SS income & 3751.0 & 756 & 0.4368 & 0.3851 & - & - & - & — \\
\hline s.e. & & & 0.0164 & 0.0161 & - & - & - & - \\
\hline $90^{t h}$ Pct SS income & 7423.9 & 756 & 0.2912 & 0.2584 & - & - & - & - \\
\hline s.e. & & & 0.0165 & 0.0162 & - & - & - & - \\
\hline Income & 7163.3 & 756 & - & - & 0.0240 & 0.0253 & 0.0562 & 0.0679 \\
\hline s.e. & & & - & 一 & 0.0153 & 0.0144 & 0.0357 & 0.0386 \\
\hline Rel. Inc. poverty ${ }^{a}$ & 3134.2 & 756 & - & 一 & -0.5451 & -0.5152 & -1.4205 & -1.4718 \\
\hline s.e. & & & - & - & 0.0636 & 0.0605 & 0.1665 & 0.1707 \\
\hline Abs. Inc. poverty ${ }^{a}$ & 1657.6 & 756 & - & - & -0.3530 & -0.3119 & -0.9214 & -0.8922 \\
\hline s.e. & & & - & - & 0.0430 & 0.0397 & 0.1130 & 0.1126 \\
\hline $10^{\text {th }}$ income & 3419.1 & 756 & - & - & 0.0989 & 0.0997 & 0.2580 & 0.2851 \\
\hline s.e. & & & 一 & - & 0.0103 & 0.0089 & 0.0281 & 0.0274 \\
\hline $50^{\text {th }}$ income & 6167.7 & 756 & - & - & 0.0176 & 0.0126 & 0.0402 & 0.0328 \\
\hline s.e. & & & - & - & 0.0148 & 0.0127 & 0.0341 & 0.0333 \\
\hline $90^{\text {th }}$ income & 11819 & 756 & - & 一 & -0.0154 & -0.0096 & -0.0534 & -0.0376 \\
\hline s.e. & & & - & 一 & 0.0243 & 0.0236 & 0.0851 & 0.0929 \\
\hline Consumption & 7345.3 & 630 & 一 & - & 0.0408 & 0.0436 & 0.0963 & 0.1161 \\
\hline s.e. & & & - & - & 0.0162 & 0.0152 & 0.0382 & 0.0406 \\
\hline Rel. cons.poverty ${ }^{a}$ & 6966.5 & 630 & - & - & -0.2958 & -0.3281 & -0.7946 & -0.9626 \\
\hline s.e. & & & - & - & 0.0949 & 0.0908 & 0.2607 & 0.2744 \\
\hline Abs. cons.poverty ${ }^{a}$ & 4786.9 & 630 & — & — & -0.2315 & -0.2746 & -0.6234 & -0.8080 \\
\hline s.e. & & & 一 & - & 0.0693 & 0.0642 & 0.1902 & 0.1954 \\
\hline $10^{\text {th }}$ consumption & 3065.5 & 756 & - & - & 0.0279 & 0.0286 & 0.0751 & 0.0842 \\
\hline s.e. & & & - & - & 0.0100 & 0.0094 & 0.0271 & 0.0277 \\
\hline $50^{t h}$ consumption & 6101.1 & 756 & — & — & 0.0366 & 0.0407 & 0.0837 & 0.1041 \\
\hline s.e. & & & - & - & 0.0135 & 0.0126 & 0.0315 & 0.0331 \\
\hline $90^{\text {th }}$ consumption & 12711 & 756 & 一 & - & 0.0356 & 0.0484 & 0.1179 & 0.1763 \\
\hline s.e. & & & 一 & 一 & 0.0262 & 0.0251 & 0.0861 & 0.0903 \\
\hline Satisfied $^{a}$ & 15596 & 756 & - & - & 0.8952 & 0.2030 & 2.1449 & 0.6272 \\
\hline s.e. & & & - & - & 0.4361 & 0.3946 & 1.0289 & 1.1022 \\
\hline Unsatisfied $^{a}$ & 2620.5 & 756 & - & - & -0.7283 & -0.5120 & -1.7688 & -1.5189 \\
\hline s.e. & & & 一 & - & 0.3512 & 0.3070 & 0.8609 & 0.8439 \\
\hline God health $^{a}$ & 36566 & 504 & - & - & -0.2974 & -0.3726 & -0.5682 & -0.8019 \\
\hline s.e. & & & - & - & 0.3447 & 0.3462 & 0.6477 & 0.7251 \\
\hline Bad health $^{a}$ & 24618 & 504 & 一 & - & -0.8693 & -0.6632 & -1.6666 & -1.4313 \\
\hline s.e. & & & - & - & 0.2954 & 0.2621 & 0.5858 & 0.5844 \\
\hline ntrols: $n$ & Statt & . & ec & $\mathrm{nc}$ & ibution & & & \\
\hline
\end{tabular}


Table 10: Well-being indicators vs benefits regressions. Age-year-gender-education cells. Benefits simulated from average covered wages by age-gender-year-education. Simulated benefit concepts: SB1B (PS) and SB2B (FS). Spain: ages 60-80+ (I). age, year and education interactions with cohort controls.

\begin{tabular}{|c|c|c|c|c|c|c|c|c|}
\hline \multirow[b]{2}{*}{ age $60^{*}$} & \multirow{2}{*}{$\begin{array}{c}\text { Mean of } \\
\text { dep. }\end{array}$} & \multirow{2}{*}{$\begin{array}{r}\# \\
\text { obs }\end{array}$} & \multicolumn{2}{|c|}{ First Stage } & \multicolumn{2}{|c|}{ Reduced Form } & \multicolumn{2}{|c|}{ IV } \\
\hline & & & PS & FS & PS & FS & $\mathrm{PS}$ & FS \\
\hline Mean SS income & 5213.0 & 1430 & 0.4213 & 0.3021 & - & - & - & - \\
\hline s.e. & & & 0.0358 & 0.0253 & - & - & - & - \\
\hline Rel Pov SS inc & 1279.1 & 727 & 0.0420 & 0.0342 & - & 一 & - & - \\
\hline s.e. & & & 0.0360 & 0.0235 & - & - & - & - \\
\hline Abs Pov SS inc & 706.4 & 515 & 0.0389 & 0.0315 & - & - & - & - \\
\hline s.e. & & & 0.0424 & 0.0291 & - & - & - & - \\
\hline $10^{t h}$ Pct SS income & 1633.4 & 1430 & 0.2174 & 0.2650 & - & 一 & - & - \\
\hline s.e. & & & 0.0314 & 0.0215 & - & 一 & - & - \\
\hline $50^{\text {th }}$ Pct SS income & 4621.1 & 1430 & 0.4743 & 0.3466 & - & - & - & - \\
\hline s.e. & & & 0.0382 & 0.0269 & - & — & 一 & — \\
\hline $90^{t h}$ Pct SS income & 9659.7 & 1430 & 0.0939 & 0.0656 & - & 一 & 一 & 一 \\
\hline s.e. & & & 0.0373 & 0.0294 & - & - & - & - \\
\hline Income & 9434.2 & 1430 & - & - & 0.3431 & 0.2249 & 0.8145 & 0.7446 \\
\hline s.e. & & & - & - & 0.0473 & 0.0340 & 0.0906 & 0.0913 \\
\hline Rel. Inc. poverty ${ }^{a}$ & 2260.2 & 1430 & - & - & -0.5392 & -0.6253 & -2.5907 & -2.4544 \\
\hline s.e. & & & - & - & 0.1560 & 0.1128 & 0.7397 & 0.4380 \\
\hline Abs. Inc. poverty ${ }^{a}$ & 1119.1 & 1430 & - & - & -0.4560 & -0.3761 & -2.0957 & -1.4180 \\
\hline s.e. & & & - & - & 0.0994 & 0.0682 & 0.5045 & 0.2709 \\
\hline $10^{t h}$ income & 4591.1 & 1430 & - & - & 0.1333 & 0.1302 & 0.6133 & 0.4915 \\
\hline s.e. & & & - & - & 0.0256 & 0.0176 & 0.1236 & 0.0681 \\
\hline $50^{\text {th }}$ income & 8448.6 & 1430 & - & - & 0.1867 & 0.1154 & 0.3936 & 0.3328 \\
\hline s.e. & & & - & - & 0.0408 & 0.0285 & 0.0765 & 0.0737 \\
\hline $90^{\text {th }}$ income & 16088 & 1430 & - & - & 0.1716 & 0.1008 & 1.8271 & 1.5373 \\
\hline s.e. & & & - & - & 0.0683 & 0.0518 & 0.8435 & 0.8600 \\
\hline Consumption & 8835.6 & 1179 & - & - & 0.1097 & 0.0924 & 0.1799 & 0.2164 \\
\hline s.e. & & & - & - & 0.0418 & 0.0306 & 0.0705 & 0.0734 \\
\hline Rel. cons.poverty ${ }^{a}$ & 4670.6 & 1179 & - & - & -0.2196 & -0.4346 & -0.7603 & -1.3516 \\
\hline s.e. & & & - & - & 0.2703 & 0.1982 & 0.9856 & 0.6574 \\
\hline Abs. cons.poverty ${ }^{a}$ & 3127.4 & 1179 & - & - & -0.4041 & -0.5107 & -1.4052 & -1.5917 \\
\hline s.e. & & & - & - & 0.2435 & 0.1718 & 0.9370 & 0.5864 \\
\hline $10^{\text {th }}$ consumption & 3926.7 & 1179 & - & - & -0.0130 & 0.0187 & -0.0496 & 0.0538 \\
\hline s.e. & & & - & - & 0.0254 & 0.0188 & 0.0863 & 0.0600 \\
\hline $50^{\text {th }}$ consumption & 7489.3 & 1179 & - & - & 0.0996 & 0.0991 & 0.1548 & 0.2086 \\
\hline s.e. & & & - & - & 0.0332 & 0.0252 & 0.0547 & 0.0576 \\
\hline $90^{\text {th }}$ consumption & 15406 & 1179 & - & - & 0.1378 & 0.1190 & 0.7570 & 1.0052 \\
\hline s.e. & & & - & - & 0.0706 & 0.0565 & 0.4430 & 0.5964 \\
\hline Satisfied $^{a}$ & 15512. & 1387 & - & - & -1.4502 & -1.8476 & -3.0778 & -6.2295 \\
\hline s.e. & & & - & - & 0.6685 & 0.5025 & 1.6683 & 1.9820 \\
\hline Unsatisfied $^{a}$ & 2521.4 & 1387 & - & - & -0.2001 & 0.0547 & -0.6848 & -0.1771 \\
\hline s.e. & & & - & - & 0.2753 & 0.2075 & 0.6966 & 0.7385 \\
\hline God health $^{a}$ & 42086. & 666 & - & - & -0.0767 & -2.1577 & -0.5157 & -11.1284 \\
\hline s.e. & & & - & - & 1.1914 & 0.8857 & 3.5396 & 7.2493 \\
\hline Bad health $^{a}$ & 21897. & 666 & - & - & -1.7998 & 0.1163 & -5.3532 & 0.6071 \\
\hline s.e. & & & - & - & 1.1009 & 0.8333 & 4.3102 & 4.2293 \\
\hline $\begin{array}{l}\text { Cohort controls: } \\
\text { Standard errors }\end{array}$ & statu & hd & du & dis & butions & & & \\
\hline
\end{tabular}


Table 11: Well-being indicators vs benefits regressions. Age-gender-year cells. Simulated benefit concepts: minimum pension entitlement (SB3), and average non-contributive benefit per elder person. Spain: ages 60-80+. Linear age and year specification with cohort controls.

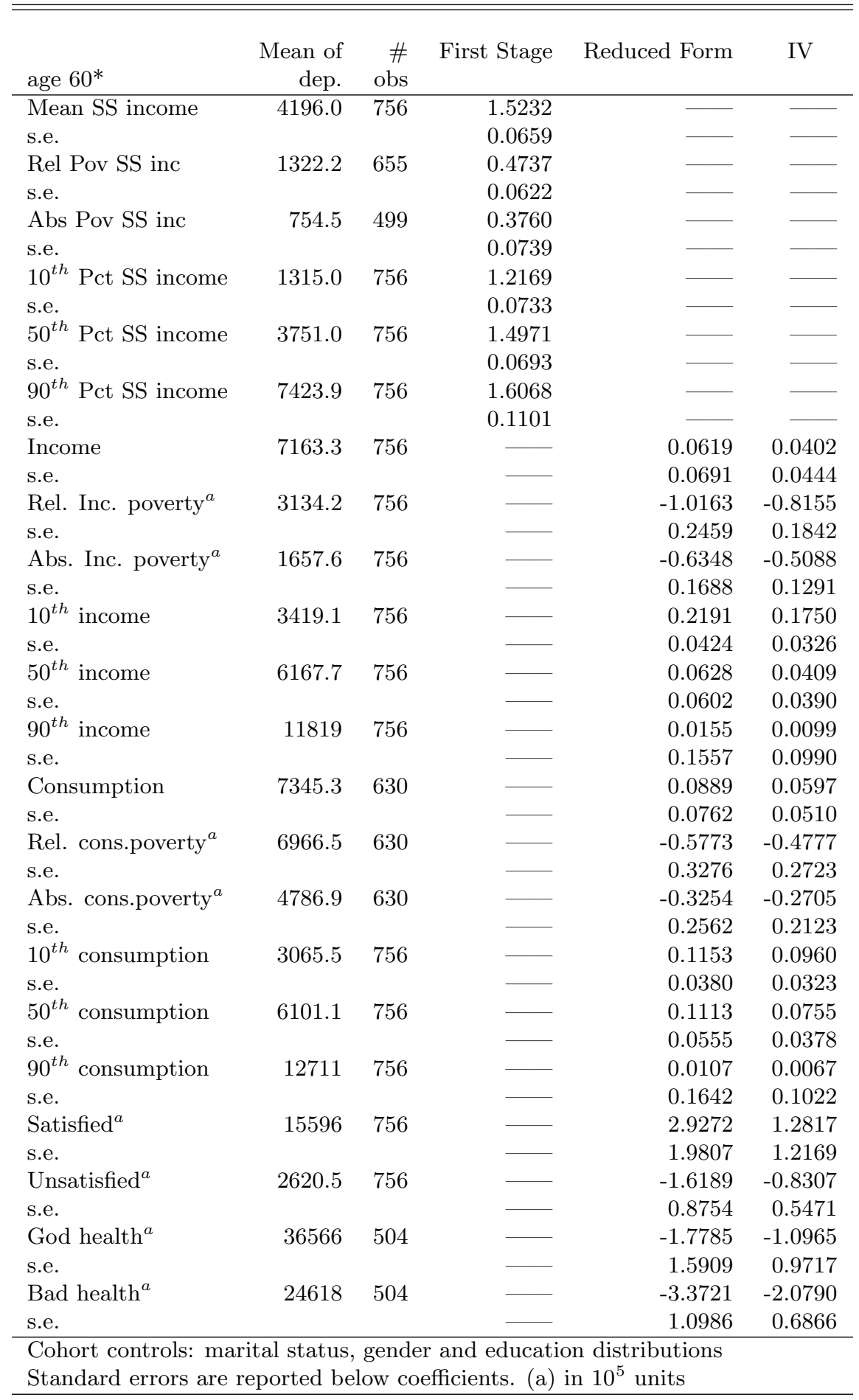


sizeable effect of SS benefit variables on income, consumption and poverty measures. Given the above it should not cause any surprise that the clearer results are found for the 10th percentile and poverty measures. Results for satisfaction and health variable, while showing the correct sign are not, as a rule, significant.

\section{Conclusions}

Apparently, the Spanish pension system has not witnessed any big change during the period 19852000. Further, since 1975, only modifications of the pension formula are of some relevance. In fact, the most important changes in the system have been the increase in the generosity of the minimum pension and survival pension, and the introduction of non-contributive pension. Minimum pension supplements and non-contributive pension (mostly for women) represent well above 10 percent of pension expenditure, which helps understand the continuous improvement of the Spanish elderly.

In our econometric analysis we are able to find sizeable effects of the SS benefit variables on income, consumption and poverty measures for the Spanish elderly. Not surprisingly, in light of our earlier discussion, the clearer and stronger results are found for individuals in the 10th percentile and for poverty measures. When measures of personal satisfaction and health conditions are on the left hand side the estimated coefficients, while showing the correct sign, are not, as a rule, statistically significant. 


\section{References}

Arriba, A. and L. Moreno "Spain: poverty, social exclusion and safety nets", Documento 02-10, Unidad de Políticas Comparadas, CSIC, 2002.

Barrada, A. El Gasto Público de Bienestar Social en España de 1964 a 1995, Fundación BBV, Madrid, 1999.

Boldrin, M., S. Jiménez-Martín and F. Peracchi (1999) "Social Security and Retirement in Spain", in J. Gruber and D. Wise (eds.), Social Security Programs and Retirement around the World, Chicago University Press for the NBER.

Boldrin, M., S. Jiménez-Martín and F. Peracchi (2001) Sistema de Pensiones y Mercado de Trabajo en España, Fundación BBVA, Madrid.

Boldrin, M., S. Jiménez-Martín and F. Peracchi (2004) "Micro-modeling of Retirement Behavior in Spain", in J. Gruber, and D. Wise (eds.), Social Security and Retirement around the World: Microestimations, Chicago University Press for the NBER .

Instituto Nacional de Estadística, INE (1995), Proyecciones de la Población de España, Madrid.

Instituto Nacional de Estadística, INE (2002), Tablas de Mortalidad de la Población Española, Madrid.

Instituto Nacional de Estadística, INE, Encuesta de Población Activa. Microdata files from 1995-II to 2001-II. Madrid.

Jiménez-Martín S. and J. Prieto (2002), "Patterns of Work and Retirement of Older Workers in Spain and Portugal," , European Review of Economics and Finance, 2002.

Jiménez-Martín S. (1999) "El impacto de la reforma de 1997 en los incentivos y la deuda implícita de la Seguridad Social", Economístas, no 84.

Ministerio de Trabajo y Asuntos Sociales, Boletín de Estadísticas Laborales. Various issues.

\section{A Data and Variables}

In this section we define the variables that have been employed in the specification of the reduced form probit. The data source is the HLSS, unless we state otherwise.

\section{Data Sources}

European Community Household Panel. The ECHP is a PSID-like survey which started in 1994 and ends with the 2001 wave. The sample size for Spain is over +7000 households ( +17800 individuals).

Budget surveys:

Encuesta de Presupuestos Familiares: The EPF is a cross-sectional household budget survey carried out by INE in 1973-74, 1980-81 and 1990-91, with reference to income (classified by sources), consumption expenditure, and dwelling characteristics in the previous calendar year. The 1990-91 sample contains 21,155 households and 72,123 persons (56582 of them $16+$ ).

Encuesta continua de presupuestos familiares (Household budget Continuous Survey): This is a rotating household survey carried out quarterly by INE since 1985. It collects data on income, consumption and personal characteristic for about 3,000 households. One eight of the sample is 
replaced at each rotation. The Household Budget Continuous Survey, started by INE in January 1985, provides quarterly and annual information on the origin and amount of households incomes, and the way they are used in several consumption expenditures. We dispose of data for the 1985-96 period. The ECPF 1997, started in the second quarter of 1997, replaces both the ECPF 1985 and the EPF. The objectives of the new survey are the sum of those of the two surveys that the new ECPF replaces.

EPA: A quarterly CPS-like survey of roughly 60,000 Spanish households. It contains fairly detailed information on labor force status, education and family background variables but no information on wages and income. Publicly released cross-sectional files are available from 1976 onward. Starting with 1987, INE also releases the so called Encuesta de Población Activa Enlazada or EPAL, which is the panel version of EPA obtained by exploiting the rotating cross-section nature of the origin al survey. It contains fewer variables than EPA, but it permits to follow individuals for up to 6 consecutive quarters.

Eurobarometer (EB): An annual pan-EUropean survey on Social and Economic issues. The survey for Spain started in 1985, and has been running since them. We dispose of data on the 1985-2002.

Encuesta Nacional de Salud (ENS): 1987-1993-1995-1997-2001. Centro de Investigaciones Sociológicas.

Benefit file form Labor Histories (from the HLSS sample): For each individual in the HLSS (see Boldrin et al, 2004, for a description) file who has received some benefits at any point in time, we know most of the information that the SS administration uses to compute the monthly benefits to be paid. In particular, we know the initial and current pension, the benefit base (base reguladora), the number of contributive years, current integration to the minimum pension (complementos por el minimo), the date of claiming, the date of award, the type of benefits, etcetera. 